\title{
FACT is recruited to the +1 nucleosome of transcribed genes and spreads in a Chd1-dependent manner
}

\author{
Célia Jeronimo ${ }^{1}$, Andrew Angel ${ }^{2}$, Christian Poitras ${ }^{1}$, Pierre Collin ${ }^{1}$, Jane Mellor ${ }^{2}$ and François Robert ${ }^{1,3,4^{*}}$ \\ ${ }^{1}$ Institut de recherches cliniques de Montréal, 110 Avenue des Pins Ouest, Montréal, QC H2W 1R7, \\ Canada. \\ ${ }^{2}$ Department of Biochemistry, University of Oxford, South Parks Road, Oxford, OX1 3QU, UK. \\ ${ }^{3}$ Département de Médecine, Faculté de Médecine, Université de Montréal, 2900 Boul. Édouard- \\ Montpetit, Montréal, QC H3T 1J4, Canada. \\ ${ }^{4}$ Lead Contact \\ *Correspondence: francois.robert@ircm.qc.ca
}

The histone chaperone FACT occupies transcribed regions where it plays prominent roles in maintaining chromatin integrity and preserving epigenetic information. How it is targeted to transcribed regions, however, remains unclear. Proposed models for how FACT finds its way to transcriptionally active chromatin include docking on the RNA polymerase II (RNAPII) C-terminal domain (CTD), recruitment by elongation factors, recognition of modified histone tails and binding partially disassembled nucleosomes. Here, we systematically tested these and other scenarios in Saccharomyces cerevisiae and found that FACT binds transcribed chromatin, not RNAPII. Through a combination of experimental and mathematical modeling evidence, we propose that FACT recognizes the +1 nucleosome, as it is partially unwrapped by the engaging RNAPII, and spreads to downstream nucleosomes aided by the chromatin remodeler Chd1. Our work clarifies how FACT interacts with genes, suggests a processive mechanism for FACT function, and provides a framework to further dissect the molecular mechanisms of transcriptioncoupled histone chaperoning.

\section{Highlights}

- High-resolution mapping of FACT localization in yeast

- FACT binds partially unwrapped nucleosomes in transcribed genes, not RNAPII

- FACT distribution along genes requires Chd1

- Processive mechanism for FACT function

\section{Keywords}

Histone chaperone, FACT, Spt16, Pob3, Chd1, RNA polymerase II, nucleosome unwrapping 


\section{Introduction}

Nucleosomes, the building blocks of chromatin, allow for DNA compaction and the regulation of proteinDNA interactions. Nucleosomes also represent roadblocks to molecular machines that translocate along DNA. For instance, during transcription elongation, RNA polymerase II (RNAPII) encounters successions of nucleosomes, which must unfold for the DNA template to feed the polymerase active site. Importantly, however, these nucleosomes have to reassemble in the wake of the polymerase to maintain chromatin integrity (Lai and Pugh, 2017; Teves et al., 2014; Venkatesh and Workman, 2015). In yeast, this delicate process is regulated by several chromatin regulators including histone methyltransferases (Set2), histone demethylases (Rpd3S), chromatin remodelers (Chd1 and others) and histone chaperones (FACT, Spt6 and others) (Lai and Pugh, 2017; Venkatesh and Workman, 2015). Among those, histone chaperones FACT and Spt6 play master roles during transcription elongation as they can mediate both nucleosome disassembly and assembly by their capacity to bind both DNA and histones.

To assist RNAPII during transcription elongation through nucleosomes, chromatin regulators such as histone chaperones need to be recruited to sites of transcription. Most of these factors (Spt6, Set2, and Rpd3S) are recruited to these sites via their interaction with RNAPII, with important contributions from its phosphorylated C-terminal domain (CTD) (Carrozza et al., 2005; Drouin et al., 2010; Govind et al., 2010; Krogan et al., 2003; Sdano et al., 2017). How FACT makes its way to actively transcribed regions, however, remains unclear. An interaction with RNAPII or an RNAPII-associated protein would provide a simple way to recruit the histone chaperone to the right locations. Accordingly, several proteins have been proposed to recruit FACT to transcribing RNAPII, including the phosphorylated RNAPII CTD (Kwon et al., 2010; Mason and Struhl, 2003), the elongation factor PAF1 complex (PAF1C) (Adelman et al., 2006), the capping enzyme Cet1 (Sen et al., 2017), the SetD2 methyltransferase (Carvalho et al., 2013), the histone acetyltransferase NuA3 (John et al., 2000) and the chromatin remodeler Chd1 (Krogan et al., 2002), but the relative contribution of these factors to FACT recruitment has never been systematically analyzed. Alternatively, FACT may recognize transcribed chromatin rather than the elongation complex itself. Such a model would explain why FACT is recruited to transcription sites by RNAPI and III in addition to RNAPII (Birch et al., 2009; Tessarz et al., 2014). Recruitment through transcribed chromatin is supported by the recent analysis of the DNA fragments associated with FACT after micrococcal nuclease (MNase) treatment (Martin et al., 2018). These data, however, do not rule out the possibility of a transient interaction with the polymerase prior to more stable (or more easily crosslinked) interactions with nucleosomes. Also, the biochemical nature of such a "transcription-modified nucleosome" that would be recognized by FACT remains to be determined. Previous studies suggested that histone acetylation, methylation or ubiquitylation may contribute to FACT recruitment (Carvalho et al., 2013; Fleming et al., 2008; Pathak et al., 2018), potentially providing a molecular mechanism for how transcription -by co-transcriptional histone modifications- would promote the recruitment of FACT to transcribed chromatin. Alternatively, in vitro studies showing increased affinity of FACT for disrupted nucleosomes (Formosa et al., 2001; Liu et al., 2020; McCullough et al., 2018; Nesher et al., 2018; Ruone et al., 2003; Tsunaka et al., 2016; Wang et al., 2018) suggest that partial loss of histone-DNA contacts, generated by RNAPII or some associated factors, may allow FACT binding. 
Here, we systematically tested many possible recruitment mechanisms, including those proposed previously, and concluded that FACT binds transcribed chromatin rather than RNAPII or elongation factors. We, however, found no evidence for a role of histone modifications in FACT recruitment. Instead, our data support a model where partial unwrapping of the first nucleosome ( +1 nucleosome), induced by engaging RNAPII, exposes a FACT interacting surface on the nucleosome and triggers its recruitment. Once docked on the +1 nucleosome, FACT appears to spread to more downstream nucleosomes with the help of the chromatin remodeler Chd1, suggesting that FACT works processively along genes during their transcription.

\section{Results}

\section{FACT is recruited after transcription initiation in an RNAPII CTD phosphorylation-independent manner}

To start investigating how FACT is recruited to chromatin, we compared the distribution of FACT to that of RNAPII and nucleosomes at high-resolution. We performed chromatin immunoprecipitation (ChIP), followed by high-resolution tiling arrays (ChIP-chip) and sequencing exonuclease-treated ChIP (ChIP-exo) of FACT subunits (Spt16 and Pob3) and RNAPII (Rpb3) in wild type (WT) cells (Figures 1 and S1). In agreement with previous work (Martin et al., 2018; Mason and Struhl, 2003; Pathak et al., 2018; Vinayachandran et al., 2018), we found both Spt16 and Pob3 to occupy the transcribed region of transcriptionally active genes (Figures $1 \mathbf{A}$ and S1A). Both FACT subunits correlated with RNAPII occupancy (Figures 1A, 1B and S1B). Moreover, shutting down transcription using the rpb1-1 allele led to a nearly complete loss of FACT occupancy genome-wide (Figure 1C). A comparison of the data for RNAPII and Spt16 and Pob3 indicates that FACT accumulates downstream of RNAPII (Figures 1A and S1A). Indeed, FACT occupancy peaks at each nucleosome dyad within transcribed regions while RNAPII occupancy builds up upstream of the +1 nucleosome and has a more uniform distribution further downstream (Figure 1A, metagenes on the left). Thus, genome-wide FACT occupancy correlates with and depends on- transcription, but does not precisely correlate with where transcription initiates. This observation, which corroborates ChIP-exo, ChIP-seq, and MNase-ChIP-seq data by others (Martin et al., 2018; Vinayachandran et al., 2018), suggests that FACT “joins" RNAPII post-initiation.

Complete pre-initiation complexes (PICs) are too transient to be detected by ChIP in WT cells (Jeronimo and Robert, 2014; Wong et al., 2014) so that FACT may be a transient component of PICs that escapes detection in WT cells. To test this possibility, we performed RNAPII and FACT ChIP-chip experiments under two conditions that stabilize PICs: inhibition of TFIIH kinase (Kin28) and mutation of serine 5 of the RNAPII CTD. Inhibition of Kin28 and the CTD-S5A mutation both led to the accumulation of RNAPII in the promoter region as expected (Jeronimo and Robert, 2014; Wong et al., 2014) (Figures 1D and 1E). In contrast, while FACT occupancy is decreased on gene bodies (reflecting reduced RNAPII occupancy) it does not shift upstream (Figures 1D and 1E). These results do not support a direct role for FACT in transcription initiation genome-wide, although we cannot exclude roles at specific genes.

FACT has been proposed to be recruited to the elongating RNAPII via CTD phosphorylation by TFIIH (Mason and Struhl, 2003). The finding that Spt16 occupancy is unaffected by either Kin28 inhibition or 
CTD-S5A mutations (except for effects explained by changes in RNAPII occupancy) (Figures 1D and 1E), does not support such a model. Of note, we also observed no FACT occupancy defects in cells expressing CTD-S2A or CTD-S7A mutants (Figure 1E). Finally, we profiled FACT occupancy in various CTD kinase mutants including $c t k 1 \Delta, c d k 8 \Delta$, bur2 $\Delta$ and the double kin28as/bur2 $\Delta$ and found no effect on FACT occupancy that could not be solely explained by an effect on RNAPII occupancy (Figure S1C). We, therefore, conclude that FACT is unlikely to be recruited to genes via the phosphorylated CTD.

\section{FACT occupancy is uncoupled from RNAPII in CHD1 mutants}

Some evidence suggested that FACT may be recruited to the elongating RNAPII via interactions with the elongation factor PAF1C (Adelman et al., 2006), or the N-terminal domain of the capping enzyme Cet1 (Sen et al., 2017). We, therefore, tested FACT (Spt16) and RNAPII (Rpb3) occupancy by ChIP-chip in PAF1C mutants (paf1 $1, c d c 73 \Delta, r t f 1 \Delta, c t r 9 \Delta$, and leo $1 \Delta$ ), and in cells where the N-terminal domain of Cet1 is truncated (Cet1 $\Delta N$ ). None of these mutations alter FACT localization (Figures S2A and S2B). We conclude that neither the PAF1C nor the $\mathrm{N}$-terminal domain of Cet1 are required to target FACT to transcribed regions.

The data presented above are consistent with FACT occupancy on transcribed genes simply reflecting the presence of transcription, without a requirement for a recruiting factor. But what makes transcribed chromatin recognized by FACT? One possibility is that transcription generates a specific histone modification pattern that is then recognized by FACT. Several studies provided evidence for such a scenario (Fleming et al., 2008; John et al., 2000; Pathak et al., 2018; Smart et al., 2009). We therefore profiled FACT (Spt16) and RNAPII (Rpb3) occupancy by ChIP-chip in sas3 $\Delta$ (the catalytic subunit of NuA3), gcn5 $\Delta$, set2 $\Delta$, bre $1 \Delta$ (the E3 ligase for H2B ubiquitylation), ubp8 $\Delta$ (the main deubiquitylase for

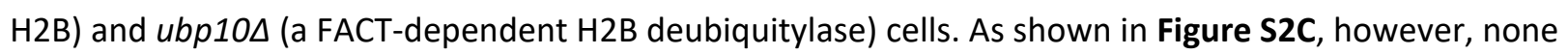
of these mutants altered FACT occupancy. We conclude that histone modifications do not contribute significantly to FACT recruitment during transcription, although we can not rule out the possibility that a modification we have not tested may contribute.

Previous work showed that FACT physically interacts with the ATP-dependent chromatin remodeler Chd1 (Farnung et al., 2017; Krogan et al., 2006; Krogan et al., 2002; Krogan et al., 2004; Simic et al., 2003). To investigate the possible role of Chd1 in FACT recruitment, we performed ChIP-chip and ChIPexo of FACT in chd1 $\triangle$ cells (Figures $2 A$ and S2D). Surprisingly, the deletion of CHD1 had a profound effect on FACT occupancy. In chd1 $\triangle$ cells, FACT occupancy increased in the $5^{\prime}$ end of genes (Figures $2 A$ and S2D). These data were observed in two different genetic backgrounds (W303 and BY4741; Figure S2D) and were not observed in mutants for the two other yeast chromatin remodelers involved in nucleosome sliding, Isw1 and Isw2 (Figure S2E). Importantly, this change in FACT occupancy occurred without a change in RNAPII occupancy (Figures 2A and S2D). Hence, FACT occupancy is uncoupled from RNAPII occupancy in chd1 $\triangle$ cells, providing direct evidence that FACT interacts with chromatin rather than with RNAPII. This conclusion is further supported by profiles of FACT occupancy in spt6-1004, a mutant of the Spt6 histone chaperone that affects histone occupancy in the 5' end of genes more so than in the 3' end (Jeronimo et al., 2019; Jeronimo et al., 2015). Indeed, in spt6-1004 cells, while RNAPII 
occupancy is reduced uniformly along genes, Spt16 and Pob3 show a biased decrease in the 5' end of genes, mirroring the occupancy defect of histones in this mutant (Figure S2F).

To determine whether Chd1 affects FACT occupancy through protein-protein interactions or through its effect on chromatin, we tested a mutant in the helicase/ATPase domain (chd1-K407R) that is predicted to prevent Chd1 from remodeling nucleosomes (Simic et al., 2003). This mutant does not affect the physical interaction of Chd1 with FACT (Figure 2B) but phenocopies the effect of chd1 $\triangle$ on FACT occupancy (Figure $\mathbf{2 C}$ ). This result strongly suggests that Chd1 impacts FACT occupancy via its effect on chromatin rather than by directly recruiting the histone chaperone. We noted, however, that even in chd1D and chd1-K407R cells, FACT occupancy correlated with transcription (Figure 2D), demonstrating that FACT recruitment is transcription-dependent even in that context.

The accumulation of FACT at the 5' end of genes when Chd1 or its remodeling activity is disrupted is inconsistent with the model that FACT simply recognizes and binds to disrupted nucleosomes wherever they occur. Instead, it suggests an unexpected mechanism in which FACT is recruited to the $5^{\prime}$ end of genes in an RNAPII-independent but transcription-dependent manner, and spreads through the gene body via a mechanism that requires the remodeling activity of Chd1. This mechanism is explored below.

\section{FACT binds disorganized nucleosomal particles on transcribed genes}

Because all our data point to recognition of altered nucleosomes produced by transcription, and, perhaps, by Chd1, as key to determining where FACT binds, we investigated the structure of the nucleosomes bound by FACT in vivo. We performed MNase-ChIP-seq of FACT (Spt16 and Pob3) in both WT and chd1 $\Delta$ cells. MNase digestion mainly generates fragments of nucleosome size ( 150 base pairs (bp)) but previous work showed that insights about non-canonical nucleosomal particles, such as partially unwrapped nucleosomes, can be obtained by analyzing DNA fragments deviating from $150 \mathrm{bp}$ (Henikoff et al., 2011; Martin et al., 2018; Ramachandran et al., 2017). We therefore scrutinized the size of the mapped DNA fragments from the FACT (Spt16 and Pob3) MNase-ChIP-seq experiments. As expected, the Input material contains mainly mononucleosomal-size DNA, with some dinucleosomes (Figures 3A, grey shades). Interestingly, however, the Spt16 ChIPs in both WT and chd1 $\Delta$ cells were enriched for DNA fragments of subnucleosomal (<150 bp) and internucleosomal (150-300 bp) sizes (Figure 3A, blue traces). The enrichment of these DNA fragments relative to mononucleosomes is even more pronounced when looking only at fragments aligning on the most highly transcribed genes (Figure 3A, right panel). Similar results were obtained with Pob3 (Figure S3A).

To systematically investigate the relationship between DNA fragment size associated with FACT and transcription, we generated heatmaps of the average fragment density over genes sorted by decreasing RNAPII occupancy ( $y$-axis) for DNA fragments from different sizes ( $x$-axis). Figure 3B clearly shows that the transcription-dependent signal in the Spt16 ChIP emanates from the internucleosomal size (150-300 $\mathrm{bp}$ and 300-450 bp) and subnucleosomal size ( $<150 \mathrm{bp}$ ) fragments, while the mononucleosomal or dinucleosomal size fragments, despite being more abundant in the sample (see distribution plots in Figure 3A), do not preferentially map to transcribed genes (similar results were obtained for Pob3, see Figure S3B). Hence, transcription-dependent FACT occupancy is reflected in the internucleosomal and 
subnucleosomal size fragments in these datasets. The mononucleosomal size fragments, which represent most of the signal (although depleted relative to the Input samples), may represent FACT binding to nucleosomes in other (non-transcriptional) contexts or, more likely, represent background signal in the ChIP. Taken together, these results show that FACT associates with disorganized nucleosomes present in transcribed regions.

\section{FACT spreads inside the gene body from the +1 nucleosome in a Chd1-dependent manner}

To determine where FACT-associated DNA fragments map relative to genes, we generated twodimensional occupancy (2DO) plots (Chereji et al., 2018; Henikoff et al., 2011) of the center of Input- and Spt16-associated fragments relative to the dyad of the +1 nucleosome in both WT and chd1 $\Delta$ cells (Figures 4A and 4B; see Figures S4A and S4B for similar experiments performed with Pob3). As expected, the Input samples are dominated by nucleosomal size fragments (150 bp) aligning with nucleosome dyads, with some dinucleosomal size fragments (300 bp) aligning between nucleosomal dyads (Figure 4A, top left panel). In addition to these dominant features, the Spt16 ChIPs from WT cells contain additional signals (notably between $150 \mathrm{bp}$ and $300 \mathrm{bp}$ ) (Figure 4A, top right panel) which we showed to be the relevant signal for transcription-dependent FACT occupancy (see above). Interestingly, the plot revealed that the center of these internucleosomal size fragments covers the entire range of positions, forming an "inverted- $v$ " linking the mononucleosomal and dinucleosomal signals. This result suggests that FACT-bound particles can occupy a wide range of positions relative to canonical nucleosomal locations and that the position of these fragments is linked to their size (see Figure $\mathbf{4 C}$ for a graphical representation of representative MNase-resistant DNA fragments observed in FACT ChIP samples). Fragments forming the upward diagonal of the inverted-v share a common 5' extremity aligning with the upstream edge of their corresponding nucleosome but are increasingly longer from their $3^{\prime}$ end ascending the diagonal (Figure 4C, left panel, fragments $a-d$ ). These fragments therefore represent nucleosomal particles with extended MNase protection on the side distal to the transcription start site (TSS-distal). Conversely, the fragments along the downward diagonal have fixed 3' ends aligning with the downstream edge of their nucleosomes and variable 5' extremities (Figure 4C, right panel, fragments $d-g$ ). These fragments hence represent nucleosomal particles with extended MNase protection on the TSS-proximal side. In line with the analyses shown in Figure 3, these internucleosomal size fragments are more prominent on the most highly transcribed genes (Figure 4A, compare bottomright panel with top-right panel). We surmise those fragments represent intermediate states of FACT likely together with other factors- dynamically interacting with both sides of nucleosomes as they are being transcribed.

Interestingly, both Spt16 and Pob3 ChIPs from chd1 $\triangle$ cells yielded dramatically different patterns (Figure 4B for Spt16 and Figure S4B for Pob3). First, and in agreement with our ChIP-chip and ChIP-exo data, the MNase-ChIP-seq signal decreases from 5' to $3^{\prime}$ confirming that FACT does not distribute evenly along genes in the absence of the chromatin remodeler. Second, DNA fragments along the downward diagonal of the inverted-v (fragments $e$ and $f$ in Figure $\mathbf{4 C}$ ) are absent, suggesting that in chd1 $\Delta$ cells, FACT mostly binds nucleosomal particles with extended MNase protection on the TSS-distal side. Putting these observations together, we hypothesized that the different sized fragments represent intermediate states of a dynamic process by which FACT interacts with nucleosomes from the TSS-proximal to distal 
sides (Figures 4C and 4D). The loss of the downward inverted-v fragments reflecting binding to the downstream side of the nucleosome in chd1 $1 \Delta$ cells suggests $C h d 1$ is required for the appearance of the later stage intermediates. Also, because FACT signal logarithmically decreases at each nucleosome from $5^{\prime}$ to $3^{\prime}$ in chd1D cells (Figure S4C), the data suggest that Chd1 allows FACT to translocate from one nucleosome to the next (see Figure 4D). Both in yeast (Figure 2C) and Drosophila (Skene et al., 2014), catalytically dead Chd1 is stranded at the $5^{\prime}$ end of genes. We, therefore, propose that Chd1 uses its remodeling activity to translocate down the gene and this enables FACT to spread downstream (Figure 4D).

To gain more insights about the mechanism, we performed MNase-ChIP-seq analyses of Chd1 (WT and catalytic dead mutant (K407R)). Similar to FACT, Chd1 ChIP from MNase enriches fragments of internucleosomal sizes that correlate with transcription (Figures S3C and S3D). Interestingly, 2DO plots of these fragments suggest that Chd1 binds (protects from MNase) the TSS-distal side of nucleosomes (Figures S4D and S4E). Consistent with our ChIP-chip data, the signal is concentrated on the +1 nucleosome in chd1-K407R cells (Figure S4E). These results are consistent with biochemical and structural data (Farnung et al., 2017; Sundaramoorthy et al., 2018) and suggest possible mechanisms for how Chd1 may contribute to FACT movement (See Discussion).

\section{A mathematical model captures Chd1-dependent spreading of FACT from the +1 nucleosome}

Our model, although compatible with our and published data, assumes that the different MNaseprotected fragments bound by FACT represent intermediates of a dynamic process. It also assumes that their appearance over time follows their appearance along the inverted-v patterns (see placement of fragments in Figure 4D). A formal validation of this model would require experimental evidence for the time-dependence of the appearance of the MNase-protected fragments. Such experiments, however, are not practically doable, notably because yeast genes are very short and no efficient methods would allow us to synchronize transcription with the sufficient time scale (yeast transcription can not be synchronized using RNAPII elongation inhibitor DRB (5,6-dichloro-1- $\beta$-D-ribofuranosylbenzimidazole) as commonly done in higher eukaryotes (Jonkers and Lis, 2015)). To challenge our model against alternative ones, we turned to mathematical modeling. We built stochastic models with multiple potential mechanisms (Figures $\mathbf{5}$ and $\mathbf{S 5}$ ). Among the models tested, one (with a core "inchworm-like" mechanism of progression) was able to capture many qualitative features of the inverted-v pattern observed in the FACT MNase-ChIP data and can be summarized as follows. FACT binds at the +1 nucleosome location; extends from the downstream end in the direction of transcription; reaches full extension when encompassing the +1 and +2 nucleosome locations; transitions to a retracting state; retracts from the upstream end in the direction of transcription; reaches full retraction when encompassing the location of the +2 nucleosome; transitions to an extending state; resumes extension and repeats the extension/retraction process until the end of the gene is reached and the complex unbinds from chromatin (Figure 5A). Upon simulations, this model reached a steady-state recapitulating the characteristic inverted-v pattern observed in WT cells (Figure S5A). Adding a moderate rate of FACT unbinding at any point in the process was able to capture a shallow decrease in overall signal density towards the 3' end of genes (Figure S5B). Implementing a relatively low transition rate from the extending to retracting states, and vice-versa, captured the additional density at the apices of the 
inverted-v pattern seen in the FACT MNase-ChIP data (Figure S5C). This refined model (Figure 5B and Movie S1) recapitulates the key features of the observed FACT MNase-ChIP in WT cells. We tested alternative models, but none were as successful in recapitulating the pattern observed in the FACT MNase-ChIP data (Figures 5C, S5D-S5F). Notably, allowing FACT to bind at any nucleosome location results in increased density towards the $3^{\prime}$ end of a gene, which is not observed in the MNase-ChIP data either from WT or chd1 1 cells, suggesting that binding of FACT predominantly happens at the beginning of a gene (Figure $\mathbf{5 C}$ ).

We then took advantage of our mathematical model to test possible mechanisms for the role of Chd1. Our ChIP-chip data show that Chd1 contributes to the distribution of FACT via its ATPase activity (Figure 2C). Hence, we envisioned that Chd1 may impact on any step in the FACT dynamic process. We therefore systematically tested the impact of increasing or decreasing each variable in the model (extension, transition, retraction, unbinding; see Figures 5D, S5D-S5F). Among those simulations, impairing the extension rate recapitulated all features of the chd1 $1 \Delta$ experimental data: i) enhanced signal on the upward diagonal of the inverted-v pattern, ii) loss of the downward diagonal of the inverted-v and iii) a significant decrease in intensity towards the $3^{\prime}$ end of the gene (Figure 5D and Movie S2). Since in our mathematical model impairing the extension rate was the only change from the WT situation that recapitulates the chd1 $1 \Delta$ pattern, we can confidently propose that Chd1 promotes FACT spreading by energetically favoring the extension step, which -in biochemical terms- represents extending the MNase protection downstream of the nucleosome.

In the course of building and testing our models, we noticed that impairing the extension rate (a condition mimicking the chd1 $\Delta$ data) systematically led to the appearance of increased signal for fragments greater than $300 \mathrm{bp}$ as a natural consequence of not allowing FACT complexes to overlap (Figure S5G, left panel). Looking back at the experimental data, we noticed that such "higher-order" signal was also observed in the chd1 $\triangle$ MNase-ChIP data when displaying fragments up to 800 bp (Figure S5G, right panel). Because these fragments were not used in the construction of the mathematical model, their presence in both the simulations and the experimental data represents an internal validation of the model. In summary, our mathematical modeling data fully support a mechanism where FACT enters a gene by binding to the +1 nucleosome and spreads downstream using a cycle of steps that translate into successive extensions and retractions of the MNase-protection of the nucleosomes, with the help of Chd1. The model also suggests that Chd1 contributes most to the first (extension) step of this process.

\section{FACT recognizes partially unwrapped +1 nucleosomes induced by RNAPII}

While the data presented above provide a mechanism to explain how FACT spreads down a gene after being recruited to the +1 nucleosome, it does not explain how it is initially recruited to the +1 nucleosome of transcriptionally active genes. We addressed this question by analyzing the subnucleosomal-size DNA fragments from FACT MNase-ChIP-seq experiments. We mapped the center of DNA fragments of different sizes on the dyad of the +1 nucleosome. As previously shown in Drosophila (Ramachandran et al., 2017), the distribution of subnucleosomal-size DNA fragments from MNase-seq is bimodal and can be fit to two Gaussians, representing two populations of nucleosomes partially 
unwrapped from one end or the other (see Figure 6A for a graphical representation). Hence, guided by this previous work (Ramachandran et al., 2017), we mapped the distributions of fragments of $90 \mathrm{bp}, 103$ $\mathrm{bp}$, and $125 \mathrm{bp}$ around the dyad of the +1 nucleosome both in WT and chd1 $1 \Delta$ cells. The $90 \mathrm{bp}$ and 103 bp fragments informing on asymmetrically unwrapped nucleosomal particles and the $125 \mathrm{bp}$ fragments reflecting symmetrically unwrapped particles (Ramachandran et al., 2017). Looking at the Input material of WT cells revealed that the proportion of +1 nucleosomes partially unwrapped from the TSS-proximal side is similar to those unwrapped from the TSS-distal side, suggesting asymmetric nucleosome breathing (Figures 6B and S6A, $103 \mathrm{bp}$ and $90 \mathrm{bp}$ fragments plots for Input). As previously described (Ramachandran et al., 2017), symmetrical unwrapping is also observed, as shown through the analysis of the $125 \mathrm{bp}$ fragments (Figure 6B). Also note that similar observations were made when looking at the +2 nucleosome (Figure S6B). Subnucleosomal-size DNA fragments from the FACT ChIPs, however, were heavily biased for asymmetrically unwrapping from the TSS-proximal side (Figures 6B and S6A, 103 bp and 90 bp fragments plots for Spt16 and Pob3 ChIP) demonstrating that FACT preferentially binds to +1 nucleosomes with TSS-proximal DNA contact loss. Interestingly, similar results were observed in chd1 $\Delta$ cells, further supporting the idea that the chromatin remodeler is involved in post-recruitment steps (FACT spreading) rather than during the initial recruitment at the +1 nucleosome. Also noteworthy is that the enrichment of particles with TSS-proximal unwrapping was not observed to the same extent at the +2 nucleosome (Figure S6B), again suggesting that FACT engages the +1 nucleosome differently than it does with downstream ones. Hence, we propose that transcription-induced unwrapping of the TSSproximal side of the +1 nucleosome triggers FACT recruitment.

The analysis presented above supports the idea that RNAPII mediated unwrapping of the +1 nucleosome triggers the initial recruitment of FACT in the 5'end of transcribed genes. This model is consistent with several in vitro observations showing that while FACT does not bind intact nucleosomes, it binds to nucleosomes that are partially unwrapped by several means (see Introduction). Further support for that model came from our FACT ChIP-chip experiments in spt4 $\Delta$ cells. Spt4/Spt5 (also known as DSIF in higher eukaryotes) is an elongation factor that interacts with FACT (Foltman et al., 2013; Han et al., 2010; Lindstrom et al., 2003). Detailed in vitro analyses showed that Spt4/5 stabilizes a partially unwrapped state of the nucleosome during transcription in vitro (Crickard et al., 2017). In another study, cryo-EM revealed that Spt4/5 prevents DNA from reassociation with histones when RNAPII is stalled near the dyad (Ehara et al., 2019). Together, these two studies support a role for Spt $4 / 5$ in assisting RNAPII negotiating with nucleosomes by preventing undesirable DNA-histone interactions that may cripple the progression of the polymerase through nucleosomes, notably nucleosome +1 . Consistent with these in vitro experiments, our ChIP-chip analyses of RNAPII in spt4 $\Delta$ cells revealed an accumulation at the $5^{\prime}$ end of genes (Figure 6 C). Interestingly, FACT occupancy is decreased in spt4 $\Delta$ cells (Figure $\mathbf{6 C}$ ). This observation contrasts with other mutants we have tested (see above), where variations in RNAPII occupancy are generally mirrored by FACT. The decreased FACT recruitment in a context where RNAPII is accumulated rather suggests that Spt $4 / 5$ contributes to FACT recruitment. In light of the in vitro data mentioned above (Crickard et al., 2017), we propose that Spt $4 / 5$ contributes to the unwrapping (by preventing unsuitable rewrapping) of the +1 nucleosome, hence contributing to the proper recruitment of FACT. In the absence of Spt4/5, the unwrapping/rewrapping process is crippled, 
and undesirable DNA-histone contacts are established both blocking polymerase progression and preventing FACT recruitment.

\section{DISCUSSION}

How FACT is recruited to genes is a long-standing question that remained elusive. Here, we provide an in-depth analysis of FACT recruitment in S. cerevisiae. Using combinations of ChIP-chip, ChIP-exo, and MNase-ChIP-seq in WT and various mutants, we show that FACT binds transcribed chromatin, rather than RNAPII, in agreement with a recent report (Martin et al., 2018). Furthermore, our work supports FACT binding asymmetrically unwrapped nucleosomes at the $5^{\prime}$ end of genes as they are being approached by the polymerase. We also show that the proper distribution of FACT along genes requires the ATPase activity of the chromatin remodeler Chd1. Mathematical modeling reveals that Chd1 stimulates the initial steps of a stepwise, inchworm-like process allowing FACT to move from one nucleosome to the next. Hence, our data suggest that FACT works via a processive mechanism on the chromatin template as it is transcribed and remodeled by RNAPII and Chd1.

FACT recognizing partially unwrapped nucleosomes is consistent with a plethora of in vitro FACTnucleosome interaction data (Formosa et al., 2001; Liu et al., 2020; McCullough et al., 2018; Nesher et al., 2018; Ruone et al., 2003; Tsunaka et al., 2016; Wang et al., 2018). In vivo, partially unwrapped nucleosomes were detected in transcribed regions in Drosophila (Ramachandran et al., 2017) and yeast (this study). In addition, recent structural and biochemical studies showed DNA unwrapping from the upstream side of RNAPII-engaged nucleosomes (Farnung et al., 2018; Kujirai et al., 2018). It is therefore reasonable to think that asymmetrical DNA unwrapping of the +1 nucleosome -triggered by RNAPIIwould promote FACT recruitment. Because such partial unwrapping can be achieved multiple ways and in different circumstances in cells, the model proposed here -although elaborated looking at FACT in the context of RNAPII transcription- provides an attractive recruitment mechanism for FACT to function in different contexts. Indeed, although FACT was originally identified as a factor assisting RNAPII elongation through nucleosomes (Belotserkovskaya et al., 2003; Orphanides et al., 1998), it is involved in many nuclear processes including transcription by all three nuclear RNA polymerases, DNA replication and DNA repair (reviewed in (Formosa, 2013; Gurova et al., 2018)). In addition, FACT also works at some promoters, where it helps in transcription factor and coactivator binding and nucleosome redeposition (Biswas et al., 2006; Biswas et al., 2005; Takahata et al., 2009; Voth et al., 2014). Because nucleosomes need to unwind during all these processes, we propose that nucleosome unwrapping (mediated by different activities in each context) is triggering FACT recruitment in these settings as well. Alternative models, such as direct recruitment of FACT by the different machineries, appear unlikely as it would require FACT to specifically interact with several proteins; yet FACT is essentially composed of domains dedicated to histones and DNA interactions (reviewed in (Zhou et al., 2020)).

In addition to its role during elongation, FACT had been shown to play roles in initiation at some inducible genes (Biswas et al., 2006; Biswas et al., 2005; Takahata et al., 2009; Voth et al., 2014). Also, recent studies showed that RNAPII (Jeronimo et al., 2019; Petrenko et al., 2019) and TFIIB (Petrenko et al., 2019) occupancies are dramatically decreased at active genes when FACT subunits are disrupted. While these results may suggest a direct and global role for FACT in initiation, our data suggest 
otherwise. Indeed, we ruled out recruitment of FACT at promoters genome-wide. Hence, although we cannot exclude (and do not dispute) roles at specific promoters, our data suggest that FACT impacts initiation genome-wide indirectly via its function during elongation where it prevents cryptic transcription and the consequent titration of the transcription machinery, as previously suggested for Spt6 (Doris et al., 2018). This scenario appears plausible in the light of the recent finding that RNAPII is limiting in yeast cells (Sun et al., 2020)

Our work shows that proper distribution of FACT along genes requires the catalytic activity of Chd1. Because tampering with Chd1 affects FACT distribution but not its occupancy levels, we propose that, once recruited on chromatin at the $5^{\prime}$ end of genes, FACT translocates towards the $3^{\prime}$ end of genes with the help of Chd1. Based on MNase-ChIP-seq data and mathematical modeling, we propose that this translocation involves successions of gain and loss of contacts between FACT, histones, and DNA. The translocation of FACT is therefore likely to be coupled to its chaperone activity; that is, as it "chaperones" histones during RNAPII progression through a nucleosome, FACT makes its way from one nucleosome to the next. Our data suggest that during this process, FACT initially makes contact with a single nucleosome and progresses towards intermediates where it ultimately contacts two successive nucleosomes before letting go of the initial one. Interestingly, our mathematical modeling revealed an important role for Chd1 in the first part of this "inchworm-like" process, that is, transiting from binding to one nucleosome into simultaneously contacting two nucleosomes. It is tempting to speculate that this capacity to bind successive nucleosomes may contribute to FACT's ability to maintain proper histone modification patterns during transcription and (perhaps) replication (Jamai et al., 2009; Jeronimo et al., 2019; Jeronimo et al., 2015).

How does Chd1 remodeling activity promote FACT translocation? Consistent with our MNase-ChIP-seq data, structural studies showed that Chd1 makes contacts with downstream DNA (Farnung et al., 2017; Sundaramoorthy et al., 2018). This unique feature among remodelers is achieved through its SANT and SLIDE domains. In addition, the ATPase domain contacts DNA two superhelical turns upstream of the dyad on the TSS-proximal side and "pumps" DNA towards the dyad. This creates forces that should favor the breakage of histone-DNA contacts around the dyad and propagate DNA towards TSS-distal side. It is tempting to speculate that this process is driving FACT progression forward.

We surmise that the recently described structure of FACT binding a partially unwrapped nucleosome (Liu et al., 2020) represents the initial state of FACT binding chromatin. It is worth pointing out that the "di-nucleosome footprints" we observe in our FACT MNase-ChIP-seq data are likely to include other proteins besides FACT and histones (including Chd1, RNAPII, and other elongation factors). It is hence impossible, from our in vivo data alone, to determine whether FACT directly contacts successive nucleosomes. Our findings therefore call for the investigation of structures of FACT bound to more complex substrates (e.g. di-nucleosomes) together with Chd1, RNAPII, and perhaps other elongation factors. Several cryo-EM structures have recently been solved that should help in that venture (Ehara et al., 2019; Ehara et al., 2017; Farnung et al., 2018; Farnung et al., 2017; Kujirai et al., 2018; Liu et al., 2020; Vos et al., 2018; Vos et al., 2020; Xu et al., 2017). Collectively, the work presented here ties previous in vitro information to a relevant in vivo context (transcription) and provides a ground state for the dissection of FACT chaperoning mechanisms, both in vivo and in vitro. 


\section{ACKNOWLEDGMENTS}

We are grateful to N. Francis for critical reading of the manuscript. We also thank A. Bataille for advice about ChIP-exo library preparation and analysis; M. Sarsenova for generating strains yFR3061, yFR3084, yFR3075; O. Rocheleau-Leclair for generating strains yFR2024, yFR2035; and T. Formosa, R.A. Young, S. Hahn, S. Buratowski and F. Winston for sharing reagents. This work was funded by a grant from the Canadian Institutes of Health Research (CIHR) to F.R. (MOP-162334). This research was also enabled in part by support provided by « Calcul Québec » (http://www.calculquebec.ca) and Compute Canada (www.computecanada.ca). F.R. holds a Research Chair from the " Fonds de Recherche Québec -Santé " (FRQS). P.C. was supported by a studentship from the FRQS. A.A. was supported by a BBSRC grant to J.M. (BB/S009035/1).

\section{AUTHOR CONTRIBUTIONS}

F.R. and C.J. conceived the study and designed experiments; C.J. performed most experiments; A.A. performed the mathematical modeling; P.C. performed some ChIP-chip experiments in Figures $1 \mathrm{E}$ and S2; C.P. and F.R. performed computational data analyses; F.R. supervised research. J.M. supervised modeling. F.R. and J.M provided funding. F.R. and C.J. wrote the manuscript with input from all authors.

\section{DECLARATION OF INTERESTS}

The authors declare no competing interests.

\section{REFERENCES}

Adelman, K., Wei, W., Ardehali, M.B., Werner, J., Zhu, B., Reinberg, D., and Lis, J.T. (2006). Drosophila Paf1 modulates chromatin structure at actively transcribed genes. Mol Cell Biol 26, 250-260.

Beati, P., and Chereji, R.V. (2020). Creating 2D Occupancy Plots Using plot2DO. Methods Mol Biol 2117, 93-108.

Belotserkovskaya, R., Oh, S., Bondarenko, V.A., Orphanides, G., Studitsky, V.M., and Reinberg, D. (2003). FACT facilitates transcription-dependent nucleosome alteration. Science 301, 1090-1093.

Birch, J.L., Tan, B.C., Panov, K.I., Panova, T.B., Andersen, J.S., Owen-Hughes, T.A., Russell, J., Lee, S.C., and Zomerdijk, J.C. (2009). FACT facilitates chromatin transcription by RNA polymerases I and III. EMBO J 28, 854-865.

Biswas, D., Dutta-Biswas, R., Mitra, D., Shibata, Y., Strahl, B.D., Formosa, T., and Stillman, D.J. (2006). Opposing roles for Set2 and yFACT in regulating TBP binding at promoters. EMBO J 25, 4479-4489. Biswas, D., Yu, Y., Prall, M., Formosa, T., and Stillman, D.J. (2005). The yeast FACT complex has a role in transcriptional initiation. Mol Cell Biol 25, 5812-5822.

Carrozza, M.J., Li, B., Florens, L., Suganuma, T., Swanson, S.K., Lee, K.K., Shia, W.J., Anderson, S., Yates, J., Washburn, M.P., et al. (2005). Histone H3 methylation by Set2 directs deacetylation of coding regions by Rpd3S to suppress spurious intragenic transcription. Cell 123, 581-592.

Carvalho, S., Raposo, A.C., Martins, F.B., Grosso, A.R., Sridhara, S.C., Rino, J., Carmo-Fonseca, M., and de Almeida, S.F. (2013). Histone methyltransferase SETD2 coordinates FACT recruitment with nucleosome dynamics during transcription. Nucleic Acids Res 41, 2881-2893. 
Casper, J., Zweig, A.S., Villarreal, C., Tyner, C., Speir, M.L., Rosenbloom, K.R., Raney, B.J., Lee, C.M., Lee, B.T., Karolchik, D., et al. (2018). The UCSC Genome Browser database: 2018 update. Nucleic Acids Res 46, D762-D769.

Chereji, R.V., Ramachandran, S., Bryson, T.D., and Henikoff, S. (2018). Precise genome-wide mapping of single nucleosomes and linkers in vivo. Genome Biol 19, 19.

Collin, P., Jeronimo, C., Poitras, C., and Robert, F. (2019). RNA Polymerase II CTD Tyrosine 1 Is Required for Efficient Termination by the Nrd1-Nab3-Sen1 Pathway. Mol Cell 73, 655-669 e657.

Coulombe, C., Poitras, C., Nordell-Markovits, A., Brunelle, M., Lavoie, M.A., Robert, F., and Jacques, P.E. (2014). VAP: a versatile aggregate profiler for efficient genome-wide data representation and discovery. Nucleic Acids Res 42, W485-493.

Crickard, J.B., Lee, J., Lee, T.H., and Reese, J.C. (2017). The elongation factor Spt4/5 regulates RNA polymerase II transcription through the nucleosome. Nucleic Acids Res 45, 6362-6374.

Doris, S.M., Chuang, J., Viktorovskaya, O., Murawska, M., Spatt, D., Churchman, L.S., and Winston, F. (2018). Spt6 Is Required for the Fidelity of Promoter Selection. Mol Cell 72, 687-699 e686.

Drouin, S., Laramee, L., Jacques, P.E., Forest, A., Bergeron, M., and Robert, F. (2010). DSIF and RNA polymerase II CTD phosphorylation coordinate the recruitment of Rpd3S to actively transcribed genes. PLoS Genet 6, e1001173.

Ehara, H., Kujirai, T., Fujino, Y., Shirouzu, M., Kurumizaka, H., and Sekine, S.I. (2019). Structural insight into nucleosome transcription by RNA polymerase II with elongation factors. Science 363, 744-747.

Ehara, H., Yokoyama, T., Shigematsu, H., Yokoyama, S., Shirouzu, M., and Sekine, S.I. (2017). Structure of the complete elongation complex of RNA polymerase II with basal factors. Science 357, 921-924.

Farnung, L., Vos, S.M., and Cramer, P. (2018). Structure of transcribing RNA polymerase II-nucleosome complex. Nat Commun 9, 5432.

Farnung, L., Vos, S.M., Wigge, C., and Cramer, P. (2017). Nucleosome-Chd1 structure and implications for chromatin remodelling. Nature 550, 539-542.

Fleming, A.B., Kao, C.F., Hillyer, C., Pikaart, M., and Osley, M.A. (2008). H2B ubiquitylation plays a role in nucleosome dynamics during transcription elongation. Mol Cell 31, 57-66.

Foltman, M., Evrin, C., De Piccoli, G., Jones, R.C., Edmondson, R.D., Katou, Y., Nakato, R., Shirahige, K., and Labib, K. (2013). Eukaryotic replisome components cooperate to process histones during chromosome replication. Cell Rep 3, 892-904.

Formosa, T. (2013). The role of FACT in making and breaking nucleosomes. Biochim Biophys Acta 1819, 247-255.

Formosa, T., Eriksson, P., Wittmeyer, J., Ginn, J., Yu, Y., and Stillman, D.J. (2001). Spt16-Pob3 and the HMG protein Nhp6 combine to form the nucleosome-binding factor SPN. EMBO J 20, 3506-3517.

Govind, C.K., Qiu, H., Ginsburg, D.S., Ruan, C., Hofmeyer, K., Hu, C., Swaminathan, V., Workman, J.L., Li, B., and Hinnebusch, A.G. (2010). Phosphorylated Pol II CTD recruits multiple HDACs, including Rpd3C(S), for methylation-dependent deacetylation of ORF nucleosomes. Mol Cell 39, 234-246.

Guillemette, B., Bataille, A.R., Gevry, N., Adam, M., Blanchette, M., Robert, F., and Gaudreau, L. (2005). Variant histone H2A.Z is globally localized to the promoters of inactive yeast genes and regulates nucleosome positioning. PLoS Biol 3, e384.

Gurova, K., Chang, H.W., Valieva, M.E., Sandlesh, P., and Studitsky, V.M. (2018). Structure and function of the histone chaperone FACT - Resolving FACTual issues. Biochim Biophys Acta Gene Regul Mech 1861, 892-904.

Han, J., Li, Q., McCullough, L., Kettelkamp, C., Formosa, T., and Zhang, Z. (2010). Ubiquitylation of FACT by the cullin-E3 ligase Rtt101 connects FACT to DNA replication. Genes Dev 24, 1485-1490.

Henikoff, J.G., Belsky, J.A., Krassovsky, K., MacAlpine, D.M., and Henikoff, S. (2011). Epigenome characterization at single base-pair resolution. Proc Natl Acad Sci U S A 108, 18318-18323. 
Jamai, A., Puglisi, A., and Strubin, M. (2009). Histone chaperone spt16 promotes redeposition of the original h3-h4 histones evicted by elongating RNA polymerase. Mol Cell 35, 377-383.

Jeronimo, C., Poitras, C., and Robert, F. (2019). Histone Recycling by FACT and Spt6 during Transcription Prevents the Scrambling of Histone Modifications. Cell Rep 28, 1206-1218 e1208.

Jeronimo, C., and Robert, F. (2014). Kin28 regulates the transient association of Mediator with core promoters. Nat Struct Mol Biol 21, 449-455.

Jeronimo, C., Watanabe, S., Kaplan, C.D., Peterson, C.L., and Robert, F. (2015). The Histone Chaperones FACT and Spt6 Restrict H2A.Z from Intragenic Locations. Mol Cell 58, 1113-1123.

Jiang, C., and Pugh, B.F. (2009). A compiled and systematic reference map of nucleosome positions across the Saccharomyces cerevisiae genome. Genome Biol 10, R109.

John, S., Howe, L., Tafrov, S.T., Grant, P.A., Sternglanz, R., and Workman, J.L. (2000). The something about silencing protein, Sas3, is the catalytic subunit of NuA3, a yTAF(II)30-containing HAT complex that interacts with the Spt16 subunit of the yeast CP (Cdc68/Pob3)-FACT complex. Genes Dev 14, 1196-1208. Jonkers, I., and Lis, J.T. (2015). Getting up to speed with transcription elongation by RNA polymerase II. Nat Rev Mol Cell Biol 16, 167-177.

Krogan, N.J., Cagney, G., Yu, H., Zhong, G., Guo, X., Ignatchenko, A., Li, J., Pu, S., Datta, N., Tikuisis, A.P., et al. (2006). Global landscape of protein complexes in the yeast Saccharomyces cerevisiae. Nature 440, 637-643.

Krogan, N.J., Kim, M., Ahn, S.H., Zhong, G., Kobor, M.S., Cagney, G., Emili, A., Shilatifard, A., Buratowski, S., and Greenblatt, J.F. (2002). RNA polymerase II elongation factors of Saccharomyces cerevisiae: a targeted proteomics approach. Mol Cell Biol 22, 6979-6992.

Krogan, N.J., Kim, M., Tong, A., Golshani, A., Cagney, G., Canadien, V., Richards, D.P., Beattie, B.K., Emili, A., Boone, C., et al. (2003). Methylation of histone H3 by Set2 in Saccharomyces cerevisiae is linked to transcriptional elongation by RNA polymerase II. Mol Cell Biol 23, 4207-4218.

Krogan, N.J., Peng, W.T., Cagney, G., Robinson, M.D., Haw, R., Zhong, G., Guo, X., Zhang, X., Canadien, V., Richards, D.P., et al. (2004). High-definition macromolecular composition of yeast RNA-processing complexes. Mol Cell 13, 225-239.

Kujirai, T., Ehara, H., Fujino, Y., Shirouzu, M., Sekine, S.I., and Kurumizaka, H. (2018). Structural basis of the nucleosome transition during RNA polymerase II passage. Science 362, 595-598.

Kwon, S.H., Florens, L., Swanson, S.K., Washburn, M.P., Abmayr, S.M., and Workman, J.L. (2010). Heterochromatin protein 1 (HP1) connects the FACT histone chaperone complex to the phosphorylated CTD of RNA polymerase II. Genes Dev 24, 2133-2145.

Lai, W.K.M., and Pugh, B.F. (2017). Understanding nucleosome dynamics and their links to gene expression and DNA replication. Nat Rev Mol Cell Biol 18, 548-562.

Langmead, B., and Salzberg, S.L. (2012). Fast gapped-read alignment with Bowtie 2. Nat Methods 9, 357359.

Laughery, M.F., Hunter, T., Brown, A., Hoopes, J., Ostbye, T., Shumaker, T., and Wyrick, J.J. (2015). New vectors for simple and streamlined CRISPR-Cas9 genome editing in Saccharomyces cerevisiae. Yeast 32, 711-720.

Li, H., and Durbin, R. (2009). Fast and accurate short read alignment with Burrows-Wheeler transform. Bioinformatics 25, 1754-1760.

Li, H., Handsaker, B., Wysoker, A., Fennell, T., Ruan, J., Homer, N., Marth, G., Abecasis, G., Durbin, R., and Genome Project Data Processing, S. (2009). The Sequence Alignment/Map format and SAMtools. Bioinformatics 25, 2078-2079.

Lindstrom, D.L., Squazzo, S.L., Muster, N., Burckin, T.A., Wachter, K.C., Emigh, C.A., McCleery, J.A., Yates, J.R., 3rd, and Hartzog, G.A. (2003). Dual roles for Spt5 in pre-mRNA processing and transcription elongation revealed by identification of Spt5-associated proteins. Mol Cell Biol 23, 1368-1378. 
Liu, Y., Zhou, K., Zhang, N., Wei, H., Tan, Y.Z., Zhang, Z., Carragher, B., Potter, C.S., D'Arcy, S., and Luger, K. (2020). FACT caught in the act of manipulating the nucleosome. Nature 577, 426-431.

Martin, B.J.E., Chruscicki, A.T., and Howe, L.J. (2018). Transcription Promotes the Interaction of the FAcilitates Chromatin Transactions (FACT) Complex with Nucleosomes in Saccharomyces cerevisiae. Genetics 210, 869-881.

Mason, P.B., and Struhl, K. (2003). The FACT complex travels with elongating RNA polymerase II and is important for the fidelity of transcriptional initiation in vivo. Mol Cell Biol 23, 8323-8333.

McCullough, L.L., Connell, Z., Xin, H., Studitsky, V.M., Feofanov, A.V., Valieva, M.E., and Formosa, T. (2018). Functional roles of the DNA-binding HMGB domain in the histone chaperone FACT in nucleosome reorganization. J Biol Chem 293, 6121-6133.

Nesher, E., Safina, A., Aljahdali, I., Portwood, S., Wang, E.S., Koman, I., Wang, J., and Gurova, K.V. (2018). Role of Chromatin Damage and Chromatin Trapping of FACT in Mediating the Anticancer Cytotoxicity of DNA-Binding Small-Molecule Drugs. Cancer Res 78, 1431-1443.

Orphanides, G., LeRoy, G., Chang, C.H., Luse, D.S., and Reinberg, D. (1998). FACT, a factor that facilitates transcript elongation through nucleosomes. Cell 92, 105-116.

Pathak, R., Singh, P., Ananthakrishnan, S., Adamczyk, S., Schimmel, O., and Govind, C.K. (2018).

Acetylation-Dependent Recruitment of the FACT Complex and Its Role in Regulating Pol II Occupancy Genome-Wide in Saccharomyces cerevisiae. Genetics 209, 743-756.

Petrenko, N., Jin, Y., Dong, L., Wong, K.H., and Struhl, K. (2019). Requirements for RNA polymerase II preinitiation complex formation in vivo. elife 8 , e43654.

Quinlan, A.R., and Hall, I.M. (2010). BEDTools: a flexible suite of utilities for comparing genomic features. Bioinformatics 26, 841-842.

Ramachandran, S., Ahmad, K., and Henikoff, S. (2017). Transcription and Remodeling Produce Asymmetrically Unwrapped Nucleosomal Intermediates. Mol Cell 68, 1038-1053 e1034.

Rando, O.J. (2010). Genome-wide mapping of nucleosomes in yeast. Methods Enzymol 470, 105-118.

Ren, B., Robert, F., Wyrick, J.J., Aparicio, O., Jennings, E.G., Simon, I., Zeitlinger, J., Schreiber, J., Hannett, N., Kanin, E., et al. (2000). Genome-wide location and function of DNA binding proteins. Science 290, 2306-2309.

Rossi, M.J., Lai, W.K.M., and Pugh, B.F. (2018). Simplified ChIP-exo assays. Nat Commun 9, 2842. Ruone, S., Rhoades, A.R., and Formosa, T. (2003). Multiple Nhp6 molecules are required to recruit Spt16-Pob3 to form yFACT complexes and to reorganize nucleosomes. J Biol Chem 278, 45288-45295. Saldanha, A.J. (2004). Java Treeview--extensible visualization of microarray data. Bioinformatics 20 , 3246-3248.

Schneider, B.L., Seufert, W., Steiner, B., Yang, Q.H., and Futcher, A.B. (1995). Use of polymerase chain reaction epitope tagging for protein tagging in Saccharomyces cerevisiae. Yeast 11, 1265-1274.

Sdano, M.A., Fulcher, J.M., Palani, S., Chandrasekharan, M.B., Parnell, T.J., Whitby, F.G., Formosa, T., and Hill, C.P. (2017). A novel SH2 recognition mechanism recruits Spt6 to the doubly phosphorylated RNA polymerase II linker at sites of transcription. eLife 6, e28723.

Sen, R., Kaja, A., Ferdoush, J., Lahudkar, S., Barman, P., and Bhaumik, S.R. (2017). An mRNA Capping Enzyme Targets FACT to the Active Gene To Enhance the Engagement of RNA Polymerase II into Transcriptional Elongation. Mol Cell Biol 37, e00029-00017.

Simic, R., Lindstrom, D.L., Tran, H.G., Roinick, K.L., Costa, P.J., Johnson, A.D., Hartzog, G.A., and Arndt, K.M. (2003). Chromatin remodeling protein Chd1 interacts with transcription elongation factors and localizes to transcribed genes. EMBO J 22, 1846-1856.

Skene, P.J., Hernandez, A.E., Groudine, M., and Henikoff, S. (2014). The nucleosomal barrier to promoter escape by RNA polymerase II is overcome by the chromatin remodeler Chd1. eLife 3, e02042.

Smart, S.K., Mackintosh, S.G., Edmondson, R.D., Taverna, S.D., and Tackett, A.J. (2009). Mapping the local protein interactome of the NuA3 histone acetyltransferase. Protein Sci 18, 1987-1997. 
Sun, X.M., Bowman, A., Priestman, M., Bertaux, F., Martinez-Segura, A., Tang, W., Whilding, C., Dormann, D., Shahrezaei, V., and Marguerat, S. (2020). Size-Dependent Increase in RNA Polymerase II Initiation Rates Mediates Gene Expression Scaling with Cell Size. Curr Biol 30, 1217-1230 e1217. Sundaramoorthy, R., Hughes, A.L., El-Mkami, H., Norman, D.G., Ferreira, H., and Owen-Hughes, T. (2018). Structure of the chromatin remodelling enzyme Chd1 bound to a ubiquitinylated nucleosome. eLife 7, e35720.

Takahata, S., Yu, Y., and Stillman, D.J. (2009). FACT and Asf1 regulate nucleosome dynamics and coactivator binding at the $\mathrm{HO}$ promoter. Mol Cell 34, 405-415.

Tessarz, P., Santos-Rosa, H., Robson, S.C., Sylvestersen, K.B., Nelson, C.J., Nielsen, M.L., and Kouzarides, T. (2014). Glutamine methylation in histone H2A is an RNA-polymerase-I-dedicated modification. Nature 505, 564-568.

Teves, S.S., Weber, C.M., and Henikoff, S. (2014). Transcribing through the nucleosome. Trends Biochem Sci 39, 577-586.

Tsunaka, Y., Fujiwara, Y., Oyama, T., Hirose, S., and Morikawa, K. (2016). Integrated molecular mechanism directing nucleosome reorganization by human FACT. Genes Dev 30, 673-686.

Venkatesh, S., and Workman, J.L. (2015). Histone exchange, chromatin structure and the regulation of transcription. Nat Rev Mol Cell Biol 16, 178-189.

Vinayachandran, V., Reja, R., Rossi, M.J., Park, B., Rieber, L., Mittal, C., Mahony, S., and Pugh, B.F. (2018). Widespread and precise reprogramming of yeast protein-genome interactions in response to heat shock. Genome Res 28, 357-366.

Vos, S.M., Farnung, L., Boehning, M., Wigge, C., Linden, A., Urlaub, H., and Cramer, P. (2018). Structure of activated transcription complex Pol II-DSIF-PAF-SPT6. Nature 560, 607-612.

Vos, S.M., Farnung, L., Linden, A., Urlaub, H., and Cramer, P. (2020). Structure of complete Pol II-DSIFPAF-SPT6 transcription complex reveals RTF1 allosteric activation. Nat Struct Mol Biol 27, 668-677. Voth, W.P., Takahata, S., Nishikawa, J.L., Metcalfe, B.M., Naar, A.M., and Stillman, D.J. (2014). A role for FACT in repopulation of nucleosomes at inducible genes. PLoS One 9, e84092.

Wang, T., Liu, Y., Edwards, G., Krzizike, D., Scherman, H., and Luger, K. (2018). The histone chaperone FACT modulates nucleosome structure by tethering its components. Life Sci Alliance 1, e201800107. Wong, K.H., Jin, Y., and Struhl, K. (2014). TFIIH phosphorylation of the Pol II CTD stimulates mediator dissociation from the preinitiation complex and promoter escape. Mol Cell 54, 601-612.

Xu, Y., Bernecky, C., Lee, C.T., Maier, K.C., Schwalb, B., Tegunov, D., Plitzko, J.M., Urlaub, H., and Cramer, P. (2017). Architecture of the RNA polymerase II-Paf1C-TFIIS transcription elongation complex. Nat Commun 8, 15741.

Zhou, K., Liu, Y., and Luger, K. (2020). Histone chaperone FACT FAcilitates Chromatin Transcription: mechanistic and structural insights. Curr Opin Struct Biol 65, 26-32.

\section{FIGURE LEGENDS}

Figure 1: FACT occupies actively transcribed regions and is recruited after initiation in a CTDphosphorylation independent manner. A) Metagene and heatmap representations of RNAPII (Rpb3) and both FACT subunits (Spt16, Pob3) occupancy, as determined by ChIP-exo, in WT cells. Metagenes for all genes $(n=5,456)$ as well as the most transcribed genes (Top genes; $n=264$ ) and least transcribed (Bottom genes; $n=2,792$ ) are shown. The average enrichment level of nucleosomes (Jiang and Pugh, 2009 ) is shown in grey. Genes in the heat maps were ordered by decreasing RNAPII occupancy ( $n=$ $5,456)$. Data are aligned on the dyad position of +1 nucleosomes, as determined in (Chereji et al., 2018). 
B) Pearson correlation matrix of RNAPII (Rpb3), Spt16 and Pob3 occupancy, as determined by ChIP-exo. Pearson correlations were calculated using all of the data points covering nuclear ORFs that are longer than 1KB $(n=3503)$. C) Metagenes of RNAPII $(R p b 3$,$) and FACT (S p t 16$,$) occupancy over highly (dark$ shade; $n=85$ ), mildly (medium shade; $n=190$ ) and lowly (light shade; $n=3,241$ ) transcribed genes, as determined by ChIP-chip, relative to Input, in WT (solid traces) and rpb1-1 (dashed traces) cells after an 80 min heat-shock at $37^{\circ} \mathrm{C}$. D) Metagenes of RNAPII (Rpb3) and FACT (Spt16) occupancy over transcribed genes ( $n=275$ ), as determined by ChIP-chip, relative to Input, in WT (solid traces) and kin28 ATP analogsensitive (kin28as, dashed traces) cells, both treated 15 min with NAPP1. E) Metagenes of RNAPII (Rpb3) and FACT (Spt16) occupancy over transcribed genes $(n=355)$, as determined by ChIP-chip, relative to Input, in cells ectopically expressing the indicated CTD versions of RPB1 (WT, solid traces; S5A, dashed traces; S2A, dotted traces; S7A thin traces) following nuclear depletion of the endogenous Rpb1 protein by anchor-away (after a 90 min treatment with rapamycin, see STAR Methods). Data for RNAPII in panels D and E (except for the S2A mutant) are from (Jeronimo and Robert, 2014). NCP, nucleosome core particle. TSS, transcription start site. See also Figure $\mathbf{S 1 .}$

Figure S1: FACT occupancy correlates with transcription by RNAPII but that does not require CTD phosphorylation, related to Figure 1. A) Metagenes of RNAPII (Rpb3) and FACT (Spt16, Pob3) occupancy over highly (dark shade; $n=85$ ), mildly (medium shade; $n=190$ ) and lowly (light shade; $n=2,141$ ) transcribed genes, as determined by ChIP-chip, relative to Input, in WT cells. B) Scatter plots of Spt16 versus RNAPII (Rpb3; left), Pob3 versus RNAPII (Rpb3; middle), and Pob3 versus Spt16 (right) occupancy on ORFs ( $n=6,692)$, as determined by ChIP-chip, relative to Input, in WT cells. C) Metagenes of RNAPII (Rpb3) and FACT (Spt16, Pob3) occupancy over transcribed genes $(n=275)$, as determined by ChIP-chip, relative to Input. Top panels, WT (solid traces), $c d k 8 \Delta$ (dashed traces) and bur2 $\Delta$ (dotted traces) cells; Middle panels, WT (solid traces) and ctk1 $\Delta$ (dashed traces) cells; Bottom panels, WT (solid traces), kin28as (dashed traces) and kin28as/bur2 $\Delta$ (dotted traces) cells. WT, kin28as, and kin28as/bur2 $\Delta$ cells in the bottom panels were treated 15 min with NAPP1.

Figure 2: FACT, but not RNAPII, accumulates at 5' nucleosomes in CHD1 mutants. A) Metagene representation of RNAPII (Rpb3) and FACT (Spt16, Pob3) occupancy over genes ( $n=5,456)$, as determined by ChIP-exo, in WT (solid traces) and chd1 $\Delta$ (dashed traces) cells. The average enrichment level of nucleosomes (Jiang and Pugh, 2009) is shown in grey. Data are aligned on the dyad position of +1 nucleosomes (Chereji et al., 2018). B) Co-immunoprecipitation experiments of FACT (Spt16) and Chd1 in WT and chd1-K407R cells expressing an HA-tagged version of Chd1. C) Metagene representation of Chd1, RNAPII (Rpb3), and FACT (Spt16) occupancy over transcribed genes ( $n=275)$, as determined by ChIP-chip, relative to Input, in WT (solid traces) and chd1-K407R (dashed traces) cells. D) Scatter plots of the ORFs occupancy ( $n=5817$ ) of FACT (Spt16) versus RNAPII (Rpb3) in WT, chd1 , and chd1-K407R cells. NCP, nucleosome core particle. TSS, transcription start site. See also Figure $\mathbf{S 2}$.

Figure S2: FACT recruitment is largely independent of PAF1C, the capping enzyme, chromatin modifiers, and chromatin remodelers but affected in chd1 $\Delta$ cells, related to Figure 2. A) Metagenes of FACT (Spt16) and RNAPII (Rpb3) occupancy over transcribed genes $(n=275)$, as determined by ChIP-chip, relative to

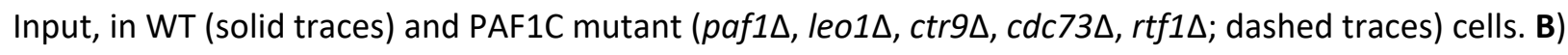
Metagenes of FACT (Spt16) and RNAPII (Rpb3) occupancy over transcribed genes ( $n=275)$, as 
determined by ChIP-chip, relative to Input, in WT (solid traces) and cet1 $\Delta \mathrm{N}$ (dashed traces) cells. C) Metagenes of FACT (Spt16) and RNAPII (Rpb3) occupancy over transcribed genes ( $n=275)$, as determined by ChIP-chip, in WT (solid traces), sas $3 \Delta, g c n 5 \Delta$, set $2 \Delta$, bre $1 \Delta, u b p 8 \Delta$ and $u b p 10 \Delta$ (dashed traces) cells. D) Metagenes of FACT (Spt16) and RNAPII (Rpb3) occupancy over transcribed genes ( $n=$ 275), as determined by ChIP-chip, relative to Input, in WT (solid traces) and chd1 $\Delta$ (dashed traces) cells from W303 and BY4741 genetic backgrounds. E) Metagenes of FACT (Spt16) and RNAPII (Rpb3) occupancy over transcribed genes $(n=275)$, as determined by ChIP-chip, relative to Input, in WT (solid traces), isw1 $\Delta$ (dashed traces, top panel) and isw2 $\Delta$ (dashed traces, bottom panel) cells. F) Metagenes of histones H2B and H4, RNAPII (Rpb3) and FACT (Spt16, Pob3) occupancy over transcribed genes ( $n=275)$, as determined by ChIP-chip, relative to Input, in WT (solid traces) and spt6-1004 (dashed traces) cells which were shifted to $37^{\circ} \mathrm{C}$ for $80 \mathrm{~min}$. Data for $\mathrm{H} 2 \mathrm{~B}$ and $\mathrm{H} 4$ are from (Jeronimo et al., 2019) and (Jeronimo et al., 2015), respectively.

Figure 3: FACT (Spt16) binds disorganized nucleosomal particles on transcribed genes. A) Distribution plots of the size of DNA fragments recovered from Input (grey area) and FACT (Spt16, blue traces) MNase-ChIP-seq samples from WT (solid traces) and chd1 $\Delta$ (dotted traces) cells for all genes ( $n=5,796$, left panel) and the top $10 \%$ transcribed genes ( $n=580$, right panel). B) Heatmap representation of Input and FACT (Spt16) average occupancy on gene body ( $n=5,796$, sorted by decreasing RNAPII occupancy on the $y$-axis) from WT and chd1 $\Delta$ cells, as determined by MNase-ChIP-seq, computed with DNA fragments from different sizes ( $x$-axis). Mono-, di- and tri-nucleosome-sized DNA fragments are indicated. See also Figure S3.

Figure S3: Analysis of the size of the mapped DNA fragments from the FACT (Pob3) and Chd1 MNaseChIP-seq experiments, related to Figure 3. A) Distribution plots of the size of DNA fragments recovered from Input (grey area) and Pob3 (violet traces) MNase-ChIP-seq samples from WT (solid traces) and chd1 $\Delta$ (dotted traces) cells. Top panel shows data for all genes $(n=5,796)$ and bottom panel shows data for the top $10 \%$ transcribed genes $(n=580)$ genes. B) Heatmap representation of Input and Pob3 average occupancy on gene body ( $n=5,796$, sorted by decreasing RNAPII occupancy on the $y$-axis) from WT and chd $1 \Delta$ cells, as determined by MNase-ChIP-seq, computed with DNA fragments from different sizes (x-axis). C) Distribution plots of the size of DNA fragments recovered from Input (grey area) and Chd1 (black traces) MNase- ChIP-seq samples from WT (solid traces) and chd1-K407R (dotted traces) cells. Top panel shows data for all genes $(n=5,796)$ and bottom panel shows data for the top $10 \%$ transcribed genes $(n=580)$ genes. D) Heatmap representation of Input and Chd1 average occupancy on gene body ( $n=5,796$, sorted by decreasing RNAPII occupancy on the $y$-axis) from WT and chd1-K407R cells, as determined by MNase- ChIP-seq, computed with DNA fragments from different sizes (x-axis). Mono-, di- and tri-nucleosome-sized DNA fragments are indicated.

Figure 4: FACT spreads inside the gene body from the +1 nucleosome in a Chd1-dependent manner. A) 2DO plots of the coverage of the sequenced fragment mid-points (nucleosome dyads) in Input (left) and Spt16 ChIP (right) from MNase-digested chromatin from WT cells, relative to the +1 nucleosome dyads. On the right of each heatmap is the distribution of the fragment sizes. Top panels show data for all genes $(n=5,796)$ and bottom panels show data for the most transcribed genes ( $n=580$, top 10\%). B) Same as panel A but for chd $1 \Delta$ cells. C) A graphical representation of the fragments aligning of the 
inverted-v's observed in 2DO plots from FACT ChIP samples. The blue diagonal lines highlight the upward and downward trajectories of the fragment mid-points for all fragments ranging from $150 \mathrm{bp}$ to $300 \mathrm{bp}$ starting from the +1 nucleosome to the $+1 /+2$ dinucleosome (left) and from the $+1 /+2$ dinucleosome to the +2 nucleosome (right) in the WT sample. Light blue lines depict the trajectory of the further downstream fragments. The red bars labeled " $a$ " through " $d$ " depict examples of fragments at different positions along the upward diagonal and the red bars labeled " $d$ " through " $g$ " depict examples of fragments at different positions along the downward diagonal. D) A working model for FACT spreading down a gene based on the MNase-ChIP-seq data in WT and chd1 $\Delta$ cells from panel A. Fragments are considered as different snapshots of a dynamic process ( $y$-axis speculatively denoted as "Time") and were ordered as they appear when walking through the inverted-v zig-zag. Note the underrepresented fragments and the progressive loss of signal in chd1 $\Delta$. See also Figure S4.

Figure S4: 2DO plots for Pob3 and Chd1 MNase-ChIP-seq experiments, related to Figure 4. A) 2DO plots of the coverage of the sequenced fragment mid-points (nucleosome dyads) in Input (left) and Pob3 ChIP (right) from MNase-digested chromatin from WT cells, relative to the +1 nucleosome dyads. On the right of each heatmap is the distribution of the fragment sizes. Top panels show data for all genes $(n=5,796)$ and bottom panels show data for the most transcribed genes $(n=580$, top 10\%). B) 2DO plots of the coverage of the sequenced fragment mid-points (nucleosome dyads) in Input (left) and Pob3 ChIP (right) from MNase-digested chromatin from chd1 $\Delta$ cells, relative to the +1 nucleosome dyads. On the right of each heatmap is the distribution of the fragment sizes. Top panels show data for all genes $(n=5,796)$ and bottom panels show data for the most transcribed genes ( $n=580$, top $10 \%$ ). C) Violin plot of the median signal from Spt16 MNase-ChIP-seq in chd1 $\Delta$ cell (data shown in Figure 4B) over the six first nucleosomes for the top $10 \%$ transcribed genes $(n=580)$. The occupancies are calculated for all fragments in the 200-300 bp interval and using a nucleosome repeat length of $161 \mathrm{bp}$ to delineate nucleosome territories. Red bars indicate the median. D) 2DO plots of the coverage of the sequenced fragment mid-points (nucleosome dyads) in Input (left) and Chd1 ChIP (right) from MNase-digested chromatin from WT cells, relative to the +1 nucleosome dyads. On the right of each heatmap is the distribution of the fragment sizes. Top panels show data for all genes $(n=5,796)$ and bottom panels show data for the most transcribed genes ( $n=580$, top 10\%). E) 2DO plots of the coverage of the sequenced fragment mid-points (nucleosome dyads) in Input (left) and Chd1 ChIP (right) from MNasedigested chromatin from chd1-K407R cells, relative to the +1 nucleosome dyads. On the right of each heatmap is the distribution of the fragment sizes. Top panels show data for all genes $(n=5,796)$ and bottom panels show data for the most transcribed genes ( $n=580$, top $10 \%$ ).

Figure 5: Mathematical modeling supports FACT binding at the +1 nucleosome and traversing the gene with an "inchworm" mechanism. A) Schematic of the inchworm mechanism. B) Simulated protected fragment sizes and locations from the basic model with constant unbinding and reduced transition rates. C) Simulated protected fragment sizes and locations from an alternative model with binding of FACT allowed at any nucleosome location within a gene. D) Simulated protected fragment sizes and locations for the same model as in A) but with a reduced rate of extension. The units of the color bars in panels B$D$ represent the number of fragments observed in a complete simulation averaged over a $20 \times 20 \mathrm{bp}$ window $\left(\times 10^{5}\right)$. See also Figure S5. 
Figure S5: Mathematical modeling indicated that many plausible mechanisms are not a good fit to the observed experimental data, related to Figure 5. A) The most basic version of the model with FACT binding at the +1 nucleosome location, extension, and retraction. B) The basic version of the model, as in A), with constant FACT unbinding. C) The basic version of the model, as in A), with reduced rates of transition between the extending and retracting states. D) The full version of the model as in Figure 5A but with mid-gene loading and constant unbinding. E) The version of the model as in D) but with higher unbinding. F) The full version of the model as in Figure 5A but with mid-gene loading, constant unbinding, and a reduced retraction rate. G) Left: The full version of the model with reduced extension to match the chd1 $\Delta$ mutant (as in Figure 5D) but depicting with larger fragment sizes up to $800 \mathrm{bp}$. Right: The experimental data for chd1 $\Delta$ cells (same as in Figure 4B, top right panel) but depicting with larger fragment sizes up to $800 \mathrm{bp}$. The units of the color bars in the simulation panels represent the number of fragments observed in a complete simulation averaged over a $20 \times 20$ bp window $\left(\times 10^{5}\right)$.

Figure 6: $\mathrm{FACT}$ recognizes +1 nucleosomes, asymmetrically unwrapped from their TSS-proximal side. A) Graphical explanation for the interpretation of the distribution plots shown in panel B. The graphs show the distribution of the center of subnucleosomal size fragments. A distribution centered at " 0 " (grey trace) indicates symmetrically unwrapped nucleosomal particles, whereas a distribution centered to the left (tan trace) or the right (green trace) indicates nucleosomal particles asymmetrically unwrapped on their TSS-distal and TSS-proximal side, respectively (see cartoons on the right with respective colors). We used $90 \mathrm{bp}, 103 \mathrm{bp}$, and $125 \mathrm{bp}$ fragments as per (Ramachandran et al., 2017). B) Distribution of 103 and $125 \mathrm{bp}(+/-5 \mathrm{bp}$ ) fragment centers (red), from Spt16 and Pob3 MNase-ChIP-seq experiments (and their Inputs) from WT and chd1 $\Delta$ cells, plotted relative to the position of +1 nucleosome dyads. The data (red) were fitted to a double-Gaussian (blue). The grey traces show the two individual Gaussians. C) Full recruitment of FACT requires Spt4/Spt5. Left: Metagene of FACT (Spt16) and RNAPII (Rpb3) occupancy over transcribed genes $(n=275)$, as determined by ChIP-chip, relative to Input, in WT (solid traces) and spt4 $\Delta$ (dashed traces) cells. Data are shown for experiments performed in two genetic backgrounds (BY4741 and W303). Right: A box plot of the average RNAPII and Spt16 occupancy in WT and spt4 $\Delta$ cells for transcribed genes $(n=275)$ from the BY4741 experiment. See also Figure $\mathbf{S 6}$.

Figure S6: Distribution of subnucleosomal-size DNA fragments from FACT MNase-ChIP-seq experiments, relative to +1 and +2 nucleosome dyads, related to Figure 6. A) Distribution of $90 \mathrm{bp}(+/-5 \mathrm{bp}$ ) fragment centers (red), from Spt16 and Pob3 MNase- ChIP-seq experiments (and their Inputs) from WT and chd1 cells, plotted relative to the position of +1 nucleosome dyads. The data (red) were fitted to a doubleGaussian (blue). The grey traces show the two individual Gaussians. B) Distribution of 90, 103, and 125 bp (+/- 5 bp) fragment centers (red), from Spt16 and Pob3 MNase-ChIP-seq experiments (and their Inputs) from WT and chd $1 \Delta$ cells, plotted relative to the position of +2 nucleosome dyads. The data was fitted to a double-Gaussian (blue). The grey traces show the two individual Gaussians.

Movie S1: Animation of the "inchworm-like" model of FACT recruitment spreading for the WT case. The left panel shows a representation of the regions of DNA protected from MNase digestion by FACT complexes for 100 realisations of a simulation across a synthetic gene. White bars represent FACT complexes, the $x$-axis is location in the gene and each track on the $y$-axis represents an individual realisation (tracks are separated by blank spaces). The right panel shows the density of fragments, of 
given sizes ( $y$-axis) and locations ( $x$-axis), protected from MNase digestion by FACT complexes as they are sampled from the simulation. Parameters of the simulation are as for the WT case as in the main text (Figure 5B and Table $\mathbf{1}$ ) except that the number of time steps shown is $10^{5}$, there are 100 realisations and there is no relaxation period prior to measurements for the protected fragments being taken.

Movie S2: Animation of the "inchworm-like" model of FACT recruitment spreading for the chd1 $\Delta$ case (same as WT except for a reduced extension rate of the FACT complex). The left panel shows a representation of the regions of DNA protected from MNase digestion by FACT complexes for 100 realisations of a simulation across a synthetic gene. White bars represent FACT complexes, the $x$-axis is location in the gene and each track on the $y$-axis represents an individual realisation (tracks are separated by blank spaces). The right panel shows the density of fragments, of given sizes (y-axis) and locations ( $x$-axis), protected from MNase digestion by FACT complexes as they are sampled from the simulation. Parameters of the simulation are as for the chd1 $\Delta$ case as in the main text (Figure 5D and Table 1) except that the number of time steps shown is $10^{5}$, there are 100 realisations and there is no relaxation period prior to measurements for the protected fragments being taken.

\section{STAR METHODS}

Detailed methods are provided in the online version of this paper and include the following:

Outline to be created by the Production team.

\section{RESOURCE AVAILABILITY}

\section{Lead Contact}

Further information and requests for resources and reagents should be directed to and will be fulfilled by the Lead Contact, François Robert (francois.robert@ircm.qc.ca).

\section{Materials Availability}

Yeast strains and plasmids generated in this study are available upon request.

\section{Data and Code Availability}

- The microarray (ChIP-chip) and DNA sequencing (ChIP-exo and MNase-ChIP-seq) data generated during this study are available at the NCBI Gene Expression Omnibus (GEO; http://www.ncbi.nlm.nih.gov/geo/) under accession number GSE155144.

- The in-house scripts used to generate some of the analyses during this study are available at https://github.com/francoisrobertlab. 
- The code related to the mathematical modeling of the MNase-ChIP-seq data is available at https://github.com/aangel-code/FACT-inchworm-model.

\section{EXPERIMENTAL MODEL AND SUBJECT DETAILS}

S. cerevisiae strains used in this study are described in Table S1. Unless otherwise indicated, cells were grown at $30^{\circ} \mathrm{C}$ and $200 \mathrm{rpm}$ in YPD (yeast extract-peptone-2\% glucose, supplemented with $44 \mu \mathrm{M}$ adenine) medium as follows. Strains were streaked from glycerol stocks onto $2 \%$ agar YPD plates and grown at $30^{\circ} \mathrm{C}$ for $2-3$ days. An isolated colony was then grown overnight in $10 \mathrm{~mL}$ of YPD. This preculture was used to inoculate $50 \mathrm{~mL}$ of YPD at an $\mathrm{OD}_{600}$ of 0.1 which was grown to an $\mathrm{OD}_{600}$ of 0.7 0.9 .

\section{METHOD DETAILS}

\section{Yeast strains and plasmids}

Genotypes for the yeast strains used in this study are listed in Table S1. HA-tag was inserted by homologous recombination of a PCR cassette amplified from the PMPY-3xHA plasmid (Schneider et al., 1995). The chd1-K407R catalytic dead point mutation (Simic et al., 2003) was introduced directly in the genome by CRISPR-Cas9 editing as previously described (Collin et al., 2019) using a pair of oligonucleotides corresponding to a gRNA targeting a region in Chd1 around amino acid K407 (see Table S2) designed for cloning into the PML107 plasmid (Laughery et al., 2015) and a PCR product obtained with repair oligonucleotides (see Table S2) containing the desired mutations (including one silent mutation destroying the protospacer adjacent motif and one creating the K407R mutation). Gene deletions were made by replacing the gene of interest with an auxotrophic or antibiotic resistance marker.

\section{Growth conditions}

For shutting off transcription experiments, a strain harboring a temperature-sensitive allele of RNAPII (rpb1-1) was grown to an $\mathrm{OD}_{600}$ of 0.7 and an equal volume of YPD pre-warmed to $49^{\circ} \mathrm{C}$ was added to the flask, which was immediately transferred to $37^{\circ} \mathrm{C}$ for additional $80 \mathrm{~min}$. For inhibition of Kin28 activity experiments, ATP analog-sensitive kin28as strains were precultured in yeast nitrogen base (YNB) medium lacking uracil before inoculation in YPD medium. kin28as strains and their controls were then grown to an $\mathrm{OD}_{600}$ of 0.8 and treated with $6 \mu \mathrm{M}$ of 1-Naphthyl PP1 (NAPP1; Tocris Bioscience) for 15 min. Strains expressing the RPB1 CTD WT or CTD mutant plasmids were grown in YNB medium lacking histidine to an $\mathrm{OD}_{600}$ of 0.5 and treated with $1 \mu \mathrm{g} / \mathrm{mL}$ of rapamycin (Bio Basic) for 90 min to anchor-away the endogenous Rpb1 protein. For the experiments involving the spt6-1004 temperature-sensitive allele, cells were grown to an $\mathrm{OD}_{600}$ of 0.5 and transferred to $37^{\circ} \mathrm{C}$ for $80 \mathrm{~min}$.

\section{ChIP}

ChIP experiments were performed from two independent biological replicates according to (Jeronimo et al., 2015). In brief, yeast cultures were grown in $50 \mathrm{~mL}$ of the appropriate medium (see above) to an $\mathrm{OD}_{600}$ of 0.7-0.9 before crosslinking with $1 \%$ formaldehyde (Fisher Scientific, BP531-500) at room 
temperature for $30 \mathrm{~min}$ and quenched with $125 \mathrm{mM}$ glycine. Crosslinked cells were collected by centrifugation and washed twice with $1 X$ TBS $(20 \mathrm{mM}$ Tris- $\mathrm{HCl} \mathrm{pH} \mathrm{7.5,} 150 \mathrm{mM} \mathrm{NaCl})$. Cell pellets were then resuspended in $700 \mu \mathrm{L}$ Lysis buffer (50 mM HEPES-KOH pH 7.5, $140 \mathrm{mM} \mathrm{NaCl}, 1 \mathrm{mM}$ EDTA, 1\% Triton X-100, 0.1\% Na-deoxycholate and protease inhibitor cocktail (1 mM PMSF, 1 mM Benzamidine, 10 $\mu \mathrm{g} / \mathrm{mL}$ Aprotinin, $1 \mu \mathrm{g} / \mathrm{mL}$ Leupeptin, $1 \mu \mathrm{g} / \mathrm{mL}$ Pepstatin)). About the same number of $\mathrm{OD}_{600}$ units was used for all samples. Cells were lysed by bead beating and the lysate was sonicated with a Model 100 Sonic dismembrator equipped with a microprobe (Fisher Scientific), 4 × $20 \mathrm{sec}$ at output 7 Watts, with a $1 \mathrm{~min}$ break between sonication cycles. Soluble fragmented chromatin was recovered by centrifugation. $600 \mu \mathrm{L}$ of the chromatin sample was taken per immunoprecipitation (IP) and, when necessary, $6 \mu \mathrm{L}$ (1\%) were saved as an Input sample. The following amounts of antibody per IP were used: anti-Spt16 (a gift from T. Formosa, $1 \mu \mathrm{L}$ ), anti-Pob3 (a gift from T. Formosa, $1 \mu \mathrm{L}$ ), anti-Rpb3 (Neoclone W0012, $3 \mu \mathrm{L}$; BioLegend 665004, $1.5 \mu \mathrm{L}$ ), anti-Flag (Sigma-Aldrich F3165, $5 \mu \mathrm{g}$ ), anti-HA (Santa Cruz Biotechnology sc7392, $15 \mu \mathrm{L}$ ) and rabbit IgG (Millipore 12-370, $2.5 \mu \mathrm{g}$ ). All antibodies have been validated for ChIP (see (Mason and Struhl, 2003) for Spt16 and Pob3 antibodies and manufacturers' web sites for commercial antibodies). Rabbit antibodies were coupled to Dynabeads coated with Protein $\mathrm{G}$ (Thermo Fisher Scientific, 10004D) and mouse antibodies were coupled to Dynabeads coated with Pan Mouse IgG antibodies (Thermo Fisher Scientific, 11042). $50 \mu \mathrm{L}$ of the appropriate Dynabeads pre-coupled with the indicated antibody were added to the chromatin sample and incubated overnight at $4^{\circ} \mathrm{C}$. Beads were washed twice with Lysis buffer, twice with Lysis buffer 500 (Lysis buffer $+360 \mathrm{mM} \mathrm{NaCl}$ ), twice with Wash buffer (10 mM Tris-HCl pH 8.0, $250 \mathrm{mM} \mathrm{LiCl,} \mathrm{0.5 \%} \mathrm{NP40,} \mathrm{0.5 \%} \mathrm{Na-deoxycholate,} 1 \mathrm{mM}$ EDTA) and once with TE (10 mM Tris-HCl pH 8.0, 1 mM EDTA). Input and immunoprecipitated chromatin were eluted and reverse-crosslinked with $50 \mu \mathrm{LTE} / \mathrm{SDS}$ (TE $+1 \% \mathrm{SDS}$ ) by incubating overnight at $65^{\circ} \mathrm{C}$. Samples were treated with RNase A (345 $\mu \mathrm{L} \mathrm{TE}, 3 \mu \mathrm{L} 10 \mathrm{mg} / \mathrm{mL}$ RNAse A, $2 \mu \mathrm{L} 20 \mathrm{mg} / \mathrm{mL}$ Glycogen) at $37^{\circ} \mathrm{C}$ for $2 \mathrm{hr}$ and subsequently subjected to Proteinase $\mathrm{K}(15 \mu \mathrm{L} 10 \% \mathrm{SDS}, 7.5 \mu \mathrm{L} 20 \mathrm{mg} / \mathrm{mL}$ Proteinase $\mathrm{K}$ ) digestion at $37^{\circ} \mathrm{C}$ for $2 \mathrm{hr}$. Samples were twice phenol/chloroform/isoamyl alcohol (25:24:1) extracted followed by precipitation with $200 \mathrm{mM} \mathrm{NaCl}$ and $70 \%$ ethanol. Precipitated DNA was resuspended in 50 $\mu \mathrm{L}$ of TE before being used in ChIP-chip experiments.

\section{ChIP-chip}

The ChIP and Input samples (see above) were blunted as follows. $40 \mu \mathrm{L}$ of ChIP DNA or about 400 ng of Input DNA were added to $70 \mu \mathrm{L}$ of blunting mix (11 $\mu \mathrm{L} 10 \mathrm{X}$ NEBuffer 2 (NEB, B7002S), $0.5 \mu \mathrm{L} 10 \mathrm{mg} / \mathrm{mL}$ BSA, $0.5 \mu \mathrm{L} 20 \mathrm{mM}$ dNTPs and $0.2 \mu \mathrm{L}$ (0.6 units) of T4 DNA polymerase (NEB, M0203L)) and incubated at $12^{\circ} \mathrm{C}$ for $20 \mathrm{~min}$. Then, the blunted DNA was extracted with phenol/chloroform/isoamyl alcohol $(25: 24: 1)$ in the presence of $280 \mathrm{mM}$ of $\mathrm{NaOAc} \mathrm{pH} 5.2$ and $10 \mu \mathrm{g}$ of glycogen, precipitated with ethanol and resuspended in $25 \mu \mathrm{LddH_{2 }}$ O. Blunted DNA was ligated to $100 \mathrm{pmol}$ of annealed linkers (see Table S2) with 2.5 units of T4 DNA ligase (Thermo Fisher Scientific, 15224041) in the supplied buffer, in a final volume of $50 \mu \mathrm{L}$, overnight at $16^{\circ} \mathrm{C}$. Samples were precipitated with $6 \mu \mathrm{L}$ of $3 \mathrm{M} \mathrm{NaOAc} \mathrm{pH} 5.2$ and 130 $\mu \mathrm{L}$ ethanol, and resuspended in $25 \mu \mathrm{L}$ dd $_{2} \mathrm{O} .15 \mu \mathrm{L}$ of labeling mix (4 $\mu \mathrm{L} 10 \mathrm{X}$ ThermoPol Reaction buffer (NEB, B9004S), $2 \mu \mathrm{L}$ of $5 \mathrm{mM}$ aa-dUTP/dNTP mix ( $5 \mathrm{mM}$ each dATP, dGTP and dCTP, $3 \mathrm{mM}$ dTTP and 2 mM 5-(3-aminoallyl)-dUTP (Thermo Fisher Scientific, AM8439)) and 1.25 $\mu \mathrm{L}$ of $40 \mu \mathrm{M}$ oligo 1) were added to each sample. Samples were placed in a thermocycler and when the temperature reached $55^{\circ} \mathrm{C}$, 
$10 \mu \mathrm{L}$ of enzyme mix ( $1 \mu \mathrm{L}$ 10X ThermoPol Reaction buffer, $1 \mu \mathrm{L}$ (5 units) Taq DNA polymerase (Thermo Fisher Scientific, 18038240) and $0.01 \mu \mathrm{L}$ (0.025 units) Pfu DNA polymerase (Thermo Fisher Scientific, EP0502)) were added and the following program was run. 1) $\left.72^{\circ} \mathrm{C}, 5 \mathrm{~min} ; 2\right) 95^{\circ} \mathrm{C}, 2 \mathrm{~min}$; 3) $32 \mathrm{cycles:}$ $\left.\left.95^{\circ} \mathrm{C}, 30 \mathrm{sec} ; 55^{\circ} \mathrm{C}, 30 \mathrm{sec} ; 72^{\circ} \mathrm{C}, 1 \mathrm{~min} ; 4\right) 72^{\circ} \mathrm{C}, 4 \mathrm{~min} ; 5\right) 4^{\circ} \mathrm{C}$, forever. PCR products were purified using QIAquick PCR Purification kit (QIAGEN, 28106) with few modifications: PE buffer was replaced by Phosphate wash buffer ( $5 \mathrm{mM} \mathrm{KPO}_{4} \mathrm{pH} 8.5$ and $80 \%$ ethanol) and EB buffer was replaced by Phosphate elution buffer ( $4 \mathrm{mM} \mathrm{KPO}_{4} \mathrm{pH}$ 8.5). Eluates were dried by SpeedVac and pellets were resuspended in 4.5 $\mu \mathrm{L}$ of freshly prepared $0.1 \mathrm{M} \mathrm{Na}_{2} \mathrm{CO}_{3} \mathrm{pH} 9.0$ buffer. $4.5 \mu \mathrm{L}$ of Cy5 Mono-Reactive NHS Ester Fluorescent Dye (ChIP samples) or Cy3 Mono-Reactive NHS Ester Fluorescent Dye (control samples Input DNA or notag ChIP) (GE Healthcare, PA25001 and PA23001) were added. Samples were incubated $1 \mathrm{hr}$ in the dark at room temperature. $35 \mu \mathrm{L}$ of $0.1 \mathrm{M} \mathrm{NaOAc} \mathrm{pH} 5.2$ were added and samples were purified using QIAquick PCR Purification kit according to the manufacturers' instructions. ChIP and control samples were combined and dried by SpeedVac. Combined samples were resuspended in $110 \mu \mathrm{L}$ of fresh hybridization mix (5 $\mu \mathrm{L} 10 \mathrm{mg} / \mathrm{mL}$ Salmon Sperm DNA (Thermo Fisher Scientific, 15632011), $5 \mu \mathrm{L} 8$ $\mathrm{mg} / \mathrm{mL}$ Yeast tRNA (Thermo Fisher Scientific, 15401011) and $100 \mu \mathrm{L}$ DIG Easy Hyb (Roche, $11603558001)$ ) and incubated $5 \mathrm{~min}$ at $95^{\circ} \mathrm{C}$ followed by $5 \mathrm{~min}$ at $45^{\circ} \mathrm{C}$. Samples were hybridized to Agilent microarrays in SureHyb enabled chambers (Agilent, G2534A) with rotation at $42^{\circ} \mathrm{C}$ for at least 18 $\mathrm{hr}$. Microarrays were washed on an orbital shaker for $5 \mathrm{~min}$ at room temperature with Wash I buffer (6X SSPE, $0.005 \% \mathrm{~N}$-Lauroylsarcosine), followed by a second wash with pre-warmed $\left(31^{\circ} \mathrm{C}\right)$ Wash II buffer (0.06X SSPE) for $5 \mathrm{~min}$ at room temperature. Microarrays were scanned using an InnoScan 900 (Innopsys) at $2 \mu \mathrm{m}$ resolution. The microarrays used were described before (Jeronimo and Robert, 2014) and were custom designed by Agilent Technologies and contain a total of about 180,000 Tm-adjusted 60 -mer probes covering the entire yeast genome with virtually no gaps between probes.

\section{ChIP-exo}

ChIP-exo experiments were performed in two biological replicates essentially as described previously (Rossi et al., 2018) with some modifications. After following our standard ChIP protocol using a crosslinked $50 \mathrm{~mL}$ cell culture at an $\mathrm{OD}_{600} \sim 0.8$ per IP and the appropriate antibody-coupled Dynabeads (see above), beads were washed twice with Lysis buffer, twice with Lysis buffer 500 , twice with Wash buffer and once with $10 \mathrm{mM}$ Tris- $\mathrm{HCl}$ pH8.0. Beads were then briefly centrifuged to remove all liquid before being used in the ChIP-exo library as follows. For A-tailing of the immunoprecipitated DNA, beads were resuspended in $50 \mu \mathrm{L}$ of $1 \mathrm{X}$ NEBuffer 2 (NEB, B7002S) containing $0.1 \mathrm{mM}$ dATP and 15 units of Klenow Fragment ( $3^{\prime} \rightarrow 5^{\prime}$ exo-) (NEB, M0212M) and incubated at $37^{\circ} \mathrm{C}$ for $30 \mathrm{~min}$. After washing the beads with $10 \mathrm{mM}$ Tris- $\mathrm{HCl} \mathrm{pH} \mathrm{8.0,} \mathrm{dA-tailed} \mathrm{DNA} \mathrm{was} \mathrm{ligated} \mathrm{to} \mathrm{the} \mathrm{First} \mathrm{adapter} \mathrm{by} \mathrm{resuspending} \mathrm{the}$ beads in $45 \mu \mathrm{L}$ of $1 \mathrm{X}$ Rapid ligation buffer (Enzymatics, B1010) containing $375 \mathrm{nM}$ of First ligation adapter (synthesized by IDT; see Table S2 for a list of adapters with their bar codes), 10 units of T4 polynucleotide kinase (NEB, M0201S) and 1,200 units of Rapid T4 DNA ligase (Enzymatics, L6030-HC-L)

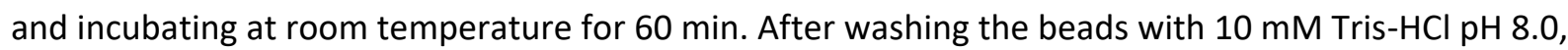
the ligated DNA was subjected to a Fill-in reaction by resuspending the beads in $40 \mu \mathrm{L}$ of $1 \mathrm{X}$ phi29 buffer (NEB) containing $0.2 \mathrm{mg} / \mathrm{mL}$ BSA (NEB), $180 \mu \mathrm{M}$ dNTPs and 10 units of phi29 DNA polymerase (NEB, $\mathrm{M0269S}$ ) and incubating at $30^{\circ} \mathrm{C}$ for $20 \mathrm{~min}$. After washing the beads with $10 \mathrm{mM}$ Tris- $\mathrm{HCl} \mathrm{pH} \mathrm{8.0,} \mathrm{DNA}$ 
was subjected to $\lambda$ exonuclease digestion by incubating the beads with $50 \mu \mathrm{L}$ of $\lambda$ exonuclease reaction buffer (NEB) containing $0.1 \%$ Triton X-100, $5 \%$ DMSO and 10 units of $\lambda$ exonuclease (NEB, M0262S) at $37^{\circ} \mathrm{C}$ for $30 \mathrm{~min}$. To elute and reverse-crosslink DNA, beads were resuspended in $40 \mathrm{uL}$ of reverse crosslink mix containing $25 \mathrm{mM}$ Tris- $\mathrm{HCl}$ pH7.5, $200 \mathrm{mM} \mathrm{NaCl}, 2 \mathrm{mM}$ EDTA, $0.5 \%$ SDS and $30 \mu \mathrm{g}$ of Proteinase K (Thermo Scientific, 25530049) and incubated at $65^{\circ} \mathrm{C}$ for $16 \mathrm{hr}$. Eluted DNA was then subjected to a 1.8X cleanup using KAPA Pure Beads (Roche, 07983280001) according to the manufacturers' instructions before proceeding with Second adapter ligation as follows. Beads were resuspended in $40 \mu \mathrm{L}$ of 1 X T4 DNA ligase reaction buffer (NEB, B0202S) containing $375 \mathrm{nM}$ of Second ligation adapter (synthesized by IDT; see Table S2) and 1,200 units of Rapid T4 DNA ligase (Enzymatics, L6030-HC-L), and incubated at room temperature for $60 \mathrm{~min}$. The ligated DNA was then subjected to a

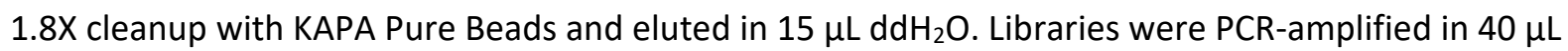
reactions with 15-18 cycles using KOD Hot Start DNA polymerase (Millipore, 71086-3) and $500 \mathrm{nM}$ of each primer P1.3 and P2.1 (synthesized by IDT; see Table S2). At this step, $10 \mu \mathrm{L}$ from each sample was further amplified for six more cycles to visualize the quality of the library by electrophoresis on a $2 \%$ TAE-agarose gel stained with ethidium bromide. Once the library validated, DNA was subjected to a $1 \mathrm{X}$ cleanup with KAPA Pure Beads, followed by a double size selection (0.6X-1X) leading to DNA fragments in the 150-450 bp range. Libraries were qualified on Agilent 2100 Bioanalyzer using High Sensitivity DNA kit (Agilent Technologies, 5067-4626) and quantified by qPCR using NEBNext Library Quant kit for Illumina (NEB, E7630). Equal molarity of each library were pooled and subjected to sequencing on an Illumina HiSeq 4000 platform at the McGill University and Génome Québec Innovation Centre to generate 50 bp paired-end reads.

\section{MNase-ChIP-seq}

MNase-ChIP experiments were performed in two biological replicates, as previously described (Rando, 2010) with minor modifications. Briefly, yeast cultures were grown in $500 \mathrm{~mL}$ of YPD to an $O D_{600}$ of 0.70.9 before crosslinking with 1\% formaldehyde (Fisher Scientific, BP531-500) at room temperature for 15 min and quenched with $125 \mathrm{mM}$ glycine at room temperature for $5 \mathrm{~min}$. Crosslinked cells were collected by centrifugation and washed twice with ice-cold $\mathrm{dd}_{2} \mathrm{O}$. Yeast cell wall digestion was then performed by resuspending cell pellets in $39 \mathrm{~mL}$ Buffer $Z(1 \mathrm{M}$ sorbitol and $50 \mathrm{mM}$ Tris- $\mathrm{HCl} \mathrm{pH} \mathrm{7.4)} \mathrm{containing} 10$ $\mathrm{mM} \beta$-mercaptoethanol and $10 \mathrm{mg}$ Zymolyase $100 \mathrm{~T}$ (US Biological, Z1004) and incubating at $30^{\circ} \mathrm{C}$ with agitation (20-40 $\mathrm{min}$ ). When digestion was completed, the resulting spheroplasts were pelleted by centrifugation at $3,000 \mathrm{~g}$ for $5 \mathrm{~min}$ at $4^{\circ} \mathrm{C}$ and gently resuspended in $2.5 \mathrm{~mL}$ of NP buffer ( $1 \mathrm{M}$ sorbitol, $50 \mathrm{mM} \mathrm{NaCl}, 10 \mathrm{mM}$ Tris- $\mathrm{HCl}$ pH 7.4, $5 \mathrm{mM} \mathrm{MgCl}, 1 \mathrm{mM} \mathrm{CaCl} 2,500 \mu \mathrm{M}$ spermidine (Sigma-Aldrich, 85558), $1 \mathrm{mM} \beta$-mercaptoethanol and $0.075 \% \mathrm{NP}-40$ ) before being exposed to MNase (Worthington, LS004798) digestion titration to generate the appropriate size of chromatin fragments as follow. $700 \mu \mathrm{l}$ of spheroplasts were incubated with 4.5, 9, 18, and 36 units of MNase (resuspended in $10 \mathrm{mM} \mathrm{Tris- \textrm {HCl }}$ $\mathrm{pH} 7.4$ and $30 \%$ glycerol) at $37^{\circ} \mathrm{C}$ for $20 \mathrm{~min}$ and the reaction was stopped by adding $10 \mathrm{mM}$ EDTA. To ensure IP conditions, $200 \mu \mathrm{L}$ of adjusting buffer (50 mM HEPES-KOH pH7.5, $140 \mathrm{mM} \mathrm{NaCl}, 1 \%$ Triton X100 , and $0.1 \% \mathrm{Na}$-deoxycholate) were added to the digested chromatin sample. To determine the appropriate condition of MNase digestion, $45 \mu \mathrm{L}(5 \%)$ of each MNase digested sample was taken and incubated with $5 \mu \mathrm{L}$ of $10 \mathrm{XTE} / \mathrm{SDS}$ at $65^{\circ} \mathrm{C}$ for $16 \mathrm{hr}$ to reverse crosslinking. Samples were then treated 
with RNase A (345 $\mu \mathrm{L} \mathrm{TE}, 3 \mu \mathrm{L} 10 \mathrm{mg} / \mathrm{mL}$ RNAse A, $2 \mu \mathrm{L} 20 \mathrm{mg} / \mathrm{mL}$ Glycogen) at $37^{\circ} \mathrm{C}$ for $2 \mathrm{hr}$ and subsequently subjected to Proteinase K (15 $\mu \mathrm{L} 10 \% \mathrm{SDS}, 7.5 \mu \mathrm{L} 20 \mathrm{mg} / \mathrm{mL}$ Proteinase $\mathrm{K}$ ) digestion at $37^{\circ} \mathrm{C}$ for $2 \mathrm{hr}$. Samples were twice phenol/chloroform/isoamyl alcohol (25:24:1) extracted followed by precipitation with $200 \mathrm{mM} \mathrm{NaCl}$ and $100 \%$ ethanol. Precipitated DNA was resuspended in $30 \mu \mathrm{L}$ of TE, treated with $1 \mu \mathrm{L}$ of $10 \mathrm{mg} / \mathrm{mL}$ RNAse $A$ at $37^{\circ} \mathrm{C}$ for $1 \mathrm{hr}$ before being analyzed by electrophoresis on a 1.8\% TAE-agarose gel stained with ethidium bromide. The digested samples were also qualified on Agilent 2100 Bioanalyzer using High Sensitivity DNA Kit (Agilent Technologies, 5067-4626). The condition giving approximately $65 \%$ mono-, $25 \%$ di- and $10 \%$ tri-nucleosomes was subjected to IP as follows. $45 \mu \mathrm{L}$ (5\%) were saved as an Input sample and the remaining digested chromatin was incubated overnight with the appropriate antibody-coupled Dynabeads as per our standard ChIP protocol (see above). Beads were then washed and samples reverse crosslinked, treated with RNase A, and subsequently subjected to Proteinase $\mathrm{K}$ before being twice phenol/chloroform/isoamyl alcohol extracted followed by precipitation with $\mathrm{NaCl}$ and ethanol. Precipitated DNA was resuspended in $50 \mu \mathrm{L}$ of TE before being used in sequencing libraries.

Before proceeding with MNase-ChIP-seq libraries, ChIP and Input samples were subjected to a $2 \mathrm{X}$ cleanup using KAPA Pure Beads (Roche, 07983280001) according to the manufacturers' instructions. Samples were eluted with $50 \mu \mathrm{L}$ of Elution buffer (10 mM Tris pH 8.0) and quantified/qualified on an Agilent 2100 Bioanalyzer instrument using the High Sensitivity DNA kit. $1 \mathrm{ng}$ of Input DNA and $40 \mu \mathrm{L}$ of ChIP DNA were used for library preparation as follows. The ends of DNA were repaired by incubating in $70 \mu \mathrm{L}$ of $1 \mathrm{X}$ NEBuffer 2 containing 0.6 units of T4 DNA polymerase (NEB, M0203L), 2 units of T4 polynucleotide kinase (NEB, M0201S), $0.09 \mathrm{nM} d N T P s$ and $0.045 \mu \mathrm{g} / \mu \mathrm{L}$ of BSA at $12^{\circ} \mathrm{C}$ for $30 \mathrm{~min}$. Repaired DNA was then subjected to a $2 X$ cleanup using KAPA Pure Beads before dA-tailing as follows. Beads containing the repaired DNA were resuspended in $50 \mu \mathrm{L}$ of $1 \mathrm{X}$ NEBuffer 2 containing $0.1 \mathrm{mM}$ dATP and 25 units of Klenow Fragment ( $3^{\prime} \rightarrow 5^{\prime}$ exo-) (NEB, M0212M), and incubated at $37^{\circ} \mathrm{C}$ for 30 min. After a 2X cleanup with KAPA Pure Beads, dA-tailed DNA was ligated to index adapters (Roche, SeqCap Adapter kit A (07141530001) and SeqCap Adapter kit B (07141548001)) as follow. The beads were resuspended in $45 \mu \mathrm{L}$ of $1 \mathrm{X}$ Ligase buffer containing $8 \mathrm{nM}$ of adapter and 2.5 units of T4 DNA ligase and incubated at room temperature for $60 \mathrm{~min}$. The ligated DNA was then subjected to a $1 \mathrm{X}$ cleanup with KAPA Pure Beads. Libraries were PCR-amplified with 10-12 cycles using KOD Hot Start DNA polymerase (Millipore, 71086-3) and cleaned up using 1X KAPA Pure Beads. Libraries were qualified on Agilent 2100 Bioanalyzer using High Sensitivity DNA kit and quantified by qPCR using NEBNext Library Quant kit for Illumina (NEB, E7630). Equal molarity of each library were pooled and subjected to sequencing on Illumina HiSeq 4000 and NovaSeq 6000 platforms at the McGill University and Génome Québec Innovation Centre to generate 50 bp paired-end reads.

\section{Co-immunoprecipitation experiments}

For co-IP experiments between Spt16 and Chd1 in WT and chd1-K407R cells, yeast strains were grown in $50 \mathrm{~mL}$ of YPD medium to an $\mathrm{OD}_{600}$ of 0.7-0.9. Cells were collected by centrifugation, washed in cold $\mathrm{ddH}_{2} \mathrm{O}$, and resuspended in $700 \mu \mathrm{L}$ of IP buffer ( $50 \mathrm{mM} \mathrm{HEPES}-\mathrm{KOH} \mathrm{pH}$ 7.5, $100 \mathrm{mM} \mathrm{NaCl}, 0.5 \mathrm{mM}$ EDTA, 0.05\% NP-40, 20\% glycerol, $1 \mathrm{mM}$ DTT and (1 mM PMSF, $1 \mathrm{mM}$ Benzamidine, $10 \mu \mathrm{g} / \mathrm{mL}$ Aprotinin, 1 $\mu \mathrm{g} / \mathrm{mL}$ Leupeptin, $1 \mu \mathrm{g} / \mathrm{mL}$ Pepstatin)). About the same amount of $\mathrm{OD}_{600}$ units was used for all samples. 
Cells were lysed by bead beating for $5 \mathrm{~min}$ and the soluble extract was recovered by centrifugation (15 $\mathrm{min}$ at $4^{\circ} \mathrm{C}$ at $\left.18,000 \times \mathrm{g}\right)$. About 3-3.5 $\mathrm{mg}$ of protein $(600 \mu \mathrm{l}$ of cleared lysate) was taken per IP and $6 \mu \mathrm{L}$ (1\%) were saved as Input sample. The cleared lysate was incubated for $60 \mathrm{~min}$ at $4^{\circ} \mathrm{C}$ with $50 \mu \mathrm{L}$ of prewashed magnetic Pan Mouse Dynabeads (Thermo Fisher Scientific) coupled to $15 \mu \mathrm{L}$ of anti-HA F7 mouse monoclonal antibody (Santa Cruz Biotechnology). Samples were then washed three times with IP buffer and resuspended in Laemmli buffer. Samples were incubated at $95^{\circ} \mathrm{C}$ for $5 \mathrm{~min}$, briefly centrifuged and analyzed by SDS-PAGE and Western blot using anti-Spt16 rabbit polyclonal (a gift from T. Formosa, 1:1000 dilution) and anti-HA mouse monoclonal (Santa Cruz Biotechnology sc-7392, 1:1000 dilution) antibodies. Membranes were incubated with donkey anti-rabbit IRDye $800 \mathrm{CW}$ and donkey antimouse IRDye 680RD antibodies (LI-COR Biosciences, 926-32213 and 926-68072) according to the manufacturers' instructions and scanned on the Odyssey infrared imaging system (LI-COR Biosciences).

\section{QUANTIFICATION AND STATISTICAL ANALYSIS}

\section{ChIP-chip Data analysis}

The ChIP-chip data were normalized using the Limma Loess method, and replicates were combined as described previously (Ren et al., 2000). The data were subjected to one round of smoothing using a Gaussian sliding window with a standard deviation of $100 \mathrm{bp}$ to generate data points in $10 \mathrm{bp}$ intervals (Guillemette et al., 2005).

\section{ChIP-exo Data analysis}

Paired-end reads from ChIP-exo data were aligned to the yeast $S$. cerevisiae genome (sacCer3 from UCSC Genome Browser) using BWA version 0.7.17 (Li and Durbin, 2009). Unmapped reads, reads not mapped properly in pairs, and duplicates were removed from the analysis using SAMtools version 1.8 (Li et al., 2009). For each paired-end read, only the first read was kept for further analysis. The aligned files were converted to BED using BEDTools version 2.28.0 (Quinlan and Hall, 2010). BED files containing reads from replicates were further analyzed individually in addition to being merged. The reads were moved 6 bp towards the $3^{\prime}$ end to correct for the offset of exonuclease stops and the site of crosslinking using a custom java script called bed-tools-j version 2.1 available at https://github.com/francoisrobertlab/bedtools-j/releases/tag/2.1 with the parameter "moveannotations $-d 6-r-d n$ ". Three genome coverage files were computed using the $5^{\prime}$ position of the moved reads with BEDTools. Coverage files were generated for reads mapping the positive strand, the negative strand, and the merged strands. The genome coverage files were converted to the bigWig format using the utilities from UCSC Genome Browser (Casper et al., 2018). The analysis was partially automated using a custom script called seqtools version 1.0 available at https://github.com/francoisrobertlab/seqtools.

\section{MNase-ChIP-seq Data analysis}

Paired-end reads from MNase-ChIP-seq data where aligned on the S. cerevisiae genome version sacCer3 using Bowtie2 version 2.3.4.3 (Langmead and Salzberg, 2012) with the parameter "-X 1000" to include longer fragments. Unmapped and low-quality fragments were removed using SAMtools version 1.9 (Li et al., 2009) with the following parameter "view -f 2 -F 2048". Duplicates were removed using SAMtools 
with the following parameters "fixmate - $m$ " and "markdup - $r$ ". The aligned files were converted to BED with BEDTools version 2.27.1 (Quinlan and Hall, 2010) using seqtools with the command "seqtools bam2bed" resulting in BED files containing the DNA fragments. The BED files of replicates were merged using seqtools with command "seqtools merge". Genome coverage files were generated using seqtools with commands "mnasetools prepgenomecov" and "seqtools genomecov" that require BEDTools version 2.27.1 and KentUtils (downloaded on July $16^{\text {th }}$ 2018). The genome coverage files were converted to the bigWig format using the utilities from UCSC Genome Browser (Casper et al., 2018). The configuration files used with seqtools for the MNase-ChIP-seq data analysis are available on GitHub at https://github.com/francoisrobertlab/mnasechip-cj2020.

\section{Heatmaps of coverage over genes versus fragment size}

To generate Figures 3B, S3B and S3D, fragments from the MNase-ChIP-seq data were grouped in bins of 10 bp using seqtools with command "seqtools split --binLength 10 --binMinLength 50 --binMaxLength 500 " and genome coverage files were generated using seqtools with commands "mnasetools prepgenomecov" and "seqtools genomecov" that require BEDTools version 2.27.1 (Quinlan and Hall, 2010) and KentUtils (downloaded on July $16^{\text {th }} 2018$ ). The heatmap matrices were then generated using seqtools with command "seqtools vap" that requires VAP (Coulombe et al., 2014) (Note: split and genome coverage must be executed prior to "seqtools vap"). Heatmaps were then generated using Java TreeView Version 1.1.6r4 (Saldanha, 2004).

\section{Two-dimensional occupancy (2DO) plots}

In Figures 4 and S4, Plot2DO (Beati and Chereji, 2020) revision number 87fadb4acd23214f83e5440b0ccb02c623fa62d9 with parameters "-t dyads -r Plus1 -I 100 -L 400 -m 0.02" was used to generate 2DO heatmaps from the MNase-ChIP-seq data. In some analyzes, the fragments not overlapping the top $10 \%$ of genes were removed using seqtools with command "seqtools intersect a Top10percentTxbdGenes.txt", where "Top10percentTxbdGenes.txt" contains the top $10 \%$ most transcribed genes and their coordinates.

\section{Identification of coordinates of +2 nucleosomes}

Coordinates of +1 nucleosomes were from (Chereji et al., 2018) while coordinates of +2 nucleosomes were determined from the chemical cleavage data (Chereji et al., 2018) as follow. BigWig dyads from (Chereji et al., 2018) were downloaded and merged using seqtools with command "seqtools mergebw". Then the position of the +2 dyad was computed using seqtools with command "seqtools dyadposition $-\mathrm{g}$ 13059_2018_1398_MOESM2_ESM.txt -s merge.bw", where "13059_2018_1398_MOESM2_ESM.txt" is the file from (Chereji et al., 2018) containing the +1 nucleosomes coordinates. The seqtools script assesses the position of the +2 nucleosome by finding the position of the maximum signal from the merged bigWig file at a distance between 141 and $191 \mathrm{bp}$ from the position of the +1 nucleosome for each gene.

\section{Distributions of MNase-ChIP-seq fragments relative to nucleosome dyads}


In Figures 6B and S6, the distribution of the center of MNase-ChIP-seq DNA fragments of different size, relative to the dyad of the +1 or +2 nucleosomes were generated as follow. The fragments from MNaseChIP-seq data were grouped in bins of 10 bp using seqtools with commands "seqtools slowsplit -binMinLength 63 --binMaxLength 73", "seqtools slowsplit --binMinLength 85 --binMaxLength 95", "seqtools slowsplit --binMinLength 98 --binMaxLength 108" and, "seqtools slowsplit --binMinLength 120 --binMaxLength 130". The genome coverage was computed from the resulting files using seqtools with command "mnasetools prepgenomecov" and then "seqtools genomecov --scale 1.0" which requires BEDTools 2.27.1 (Quinlan and Hall, 2010) and KentUtils (downloaded on July 16th 2018). The dyad coverage was computed from the genome coverage files using seqtools with command "mnasetools dyadcov -g first_dyad.txt --smoothing 20", where "first_dyad.txt" contains the position of the +1 nucleosome from (Chereji et al., 2018). The dyad coverage for the second dyad used "mnasetools dyadcov -g second_dyad.txt --smoothing 20", where "second_dyad.txt" contains the position of the +2 nucleosome from "seqtools dyadposition" execution. Gaussian fits were computed using seqtools with command "seqtools fitgaussian--svg --amin 0", while double Gaussian fits were computed using seqtools with command "seqtools fitdoublegaussian --gaussian --svg --amin1 0 --amin2 0 ". The fitting was computed using the Imfit Python library version 1.0.0 available at https://Imfit.github.io/Imfit-py/ using the GaussianModel and ConstantModel.

\section{Mathematical modeling}

Models were implemented in Matlab 2019b and used a fixed time-step stochastic algorithm in which it is assumed that only one reaction can occur in each time step. At each time step, a random number was drawn from a uniform distribution (Matlab rand() function, Mersenne Twister random number generator). This random number was then compared against a list of the cumulative summed probabilities per unit time of all possible reactions as described in the pseudo-code below (with description in roman font and pseudo code in italics). Table 1 contains parameter values and their abbreviations as used in the pseudo-code. The simulation keeps track of the number of FACT complexes and the numbers that are in the extending, retracting, fully extended and fully retracted states, FACTNo, ExtNo, RetNo, FullyExtNo and FullyRetNo, respectively.

Generate random number:

Diceroll = rand;

Compare random number against possible reactions:

if rand $<(B R)$

Bind a FACT complex at the +1 Nucleosome location (if it is unoccupied) else if rand $<\left(B R+E x t N O^{*} E R\right)$

Select a random FACT complex from those that are in the extending state and, if possible, extend by one base pair at the TSS-distal side - if the complex abuts with a preceding complex, do not extend; if the complexes leading edge reaches the end of the gene, flag as fully extended

else if rand $<\left(B R+E x t N O^{*} E R+R e t N o^{*} R R\right)$

Select a random FACT complex from those that are in the retracting state and, if possible, retract by one base pair at the TSS-proximal side 
else if rand $<(B R+E x t N o * E R+R e t N o * R R+F u l l y E x t N o * E R S)$

Select a random FACT complex from those that are in the fully extended state and

transition to the retracting state

else if rand $<\left(B R+E x t N o^{*} E R+R e t N o * R R+F u l l y E x t N O^{*} E R S+F u l l y R e t N o{ }^{*} R E S\right)$

Select a random FACT complex from those that are in the fully retracted state and

transition to the extending state - if the FACT complex has reached the end of the gene, unbind

else if rand $<(B R+$ ExtNo*ER+RetNo*RR+FullyExtNo*ERS+FullyRetNo*RES+FactNo*UBR)

Select a random FACT complex and unbind

else

Leave the system unchanged

end

The system was simulated on a synthetic gene of length 1,510 bp. Nucleosome locations were defined as regions of $150 \mathrm{bp}$, with the first at the beginning of the gene and spacing regions of $20 \mathrm{bp}$ between each nucleosome location. The minimum extent of a FACT complex was taken to be $150 \mathrm{bp}$ and the maximum to be $320 \mathrm{bp}$ (the extent of two nucleosomes and a spacing region).

The system was simulated for a relaxation period of $10^{6}$ time steps, following this the simulation was continued for an additional $10^{6}$ during which a measurement of protected fragment sizes and positions was taken every 10-time steps. Where presented in figures, the fragment sizes and positions are displayed as block averages - each displayed pixel is the mean of the 20-by-20 region around it in the original measurement. This was to increase visibility as the simulations lack noise in the positioning and size of nucleosomes and FACT complexes.

In addition to the core mechanisms described above, the possibility for new FACT complexes to bind with uniform probability to any unoccupied nucleosome location in the gene was tested.

Table 1: Parameter values, expressed as probabilities per unit time, and their abbreviations used in the main model for the WT and chd1 $\Delta$ cases (which differ only in the extension rate), and the internal binding model, see Figure 5.

\begin{tabular}{|c|c|c|c|c|}
\hline Parameter & Abbr. & WT (Fig. 5B) & $\begin{array}{c}\text { chd1 (Figs. 5D, } \\
\text { S5G) }\end{array}$ & $\begin{array}{c}\text { Internal Binding } \\
\text { (Fig. 5C) }\end{array}$ \\
\hline \multicolumn{5}{|c|}{} \\
\hline Binding & $B R$ & 0.00005 & 0.00005 & 0.00045 \\
\hline Extension & $E R$ & 0.03 & 0.0075 & 0.03 \\
\hline Extension to Retraction & $E R S$ & 0.003 & 0.003 & 0.003 \\
\hline Retraction & $R R$ & 0.03 & 0.03 & 0.03 \\
\hline Retraction to Extension & $R E S$ & 0.003 & 0.003 & 0.003 \\
\hline Unbinding & UBR & 0.000005 & 0.000005 & 0 \\
\hline \multicolumn{5}{|c|}{} \\
\hline Relaxation Time Steps & TSR & $10^{6}$ & $10^{6}$ & $10^{6}$ \\
\hline Measurement Time Steps & TSM & $10^{6}$ & $10^{6}$ & $10^{6}$ \\
\hline Measurement Interval & MI & 10 & 10 & 10 \\
\hline
\end{tabular}




\begin{tabular}{|l|c|c|c|c|} 
Realisations & $\mathrm{R}$ & 10000 & 10000 & 10000 \\
\hline
\end{tabular}

Table 2: Parameter values, expressed as probabilities per unit time used for the modelling data shown in Figure S5.

\begin{tabular}{|c|c|c|c|c|c|c|}
\hline Parameter & Fig. S5A & Fig. S5B & Fig. S5C & Fig. S5D & Fig. S5E & Fig. S5F \\
\hline \multicolumn{7}{|c|}{} \\
\hline BR & 0.00005 & 0.00005 & 0.00005 & 0.00045 & 0.00045 & 0.00045 \\
\hline ER & 0.03 & 0.003 & 0.03 & 0.03 & 0.03 & 0.03 \\
\hline ERS & 0.003 & 0.003 & 0.05 & 0.003 & 0.003 & 0.003 \\
\hline RR & 0.03 & 0.03 & 0.03 & 0.03 & 0.03 & 0.0075 \\
\hline RES & 0.0075 & 0.0075 & 0.05 & 0.003 & 0.003 & 0.003 \\
\hline UBR & 0.000005 & 0.000005 & 0.00005 & 0.00005 & 0.0005 & 0.00005 \\
\hline \multicolumn{7}{|l|}{} \\
\hline TSR & $10^{6}$ & $10^{6}$ & $10^{6}$ & $10^{6}$ & $10^{6}$ & $10^{6}$ \\
\hline TSM & $10^{6}$ & $10^{6}$ & $10^{6}$ & $10^{6}$ & $10^{6}$ & $10^{6}$ \\
\hline MI & 10 & 10 & 10 & 10 & 10 & 10 \\
\hline R & 10000 & 10000 & 10000 & 10000 & 10000 & 10000 \\
\hline
\end{tabular}

\section{KEY RESOURCE TABLE}

See accompanying document. 
A

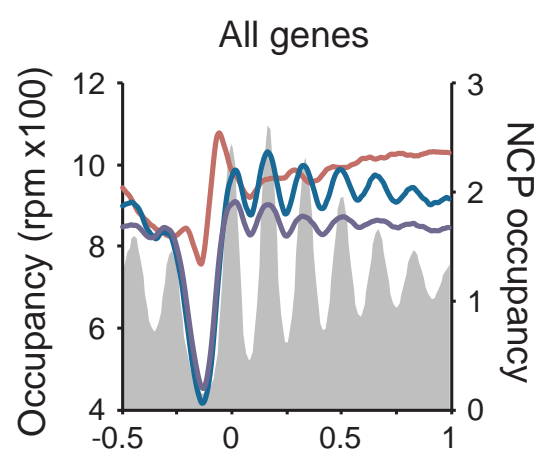

Distance from $+1 \mathrm{NCP}(\mathrm{kb})$

bioRxiv preprint doi: https://doi.org/10.1101/2020.08.20.259960; this version posted August 21, 2020. The copyright holder for this preprint (which was not certified by peer review) is the author/funder, who has granted bioRxiv a license to display the preprint in perpetuity. It is made available under aCC-BY-NC-ND 4.0 International license. RNAPII Spt16

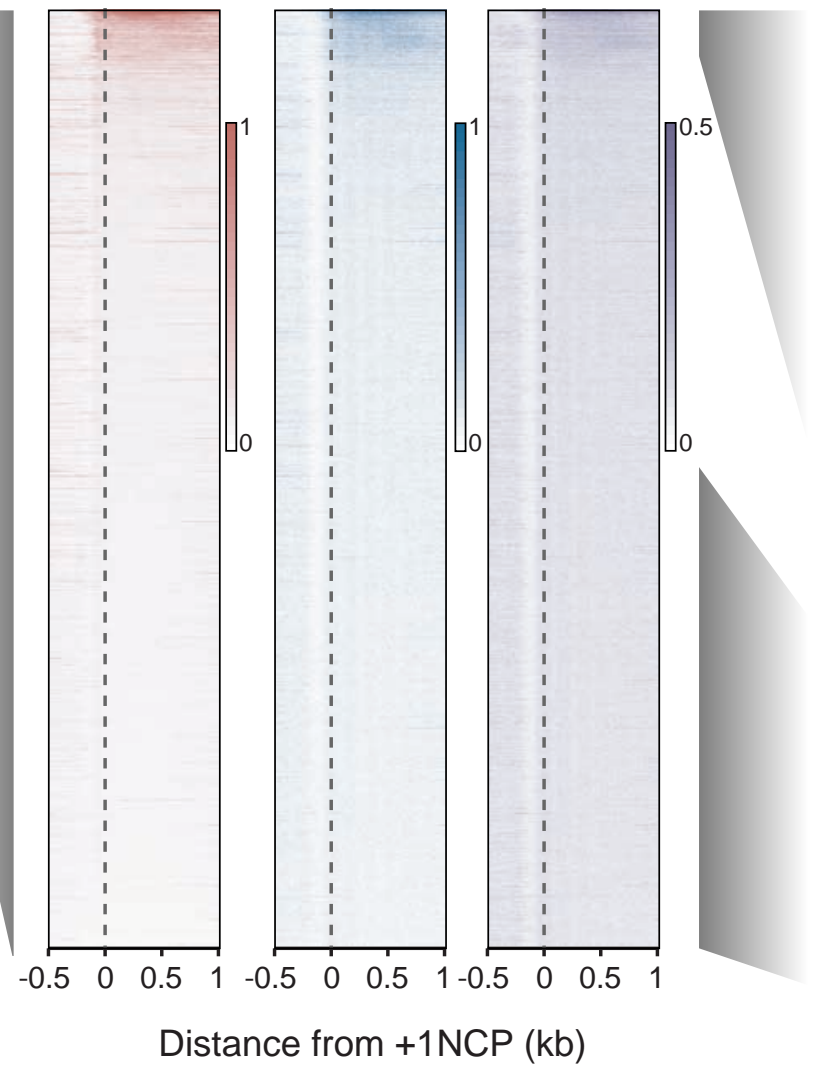

Top genes

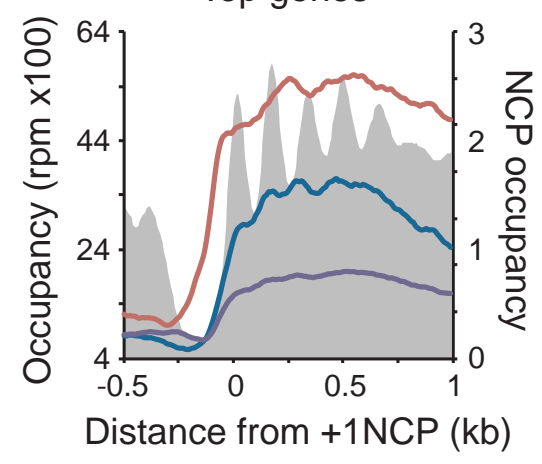

Bottom genes

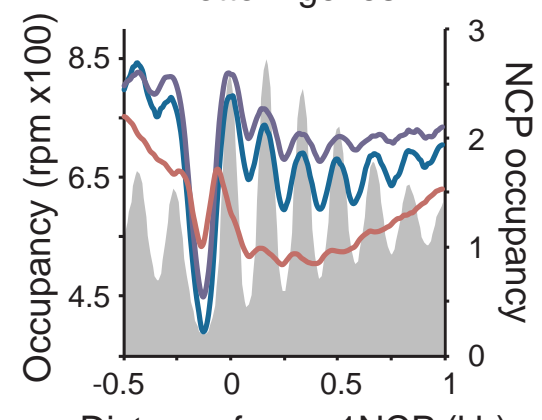

Distance from +1 NCP $(\mathrm{kb})$
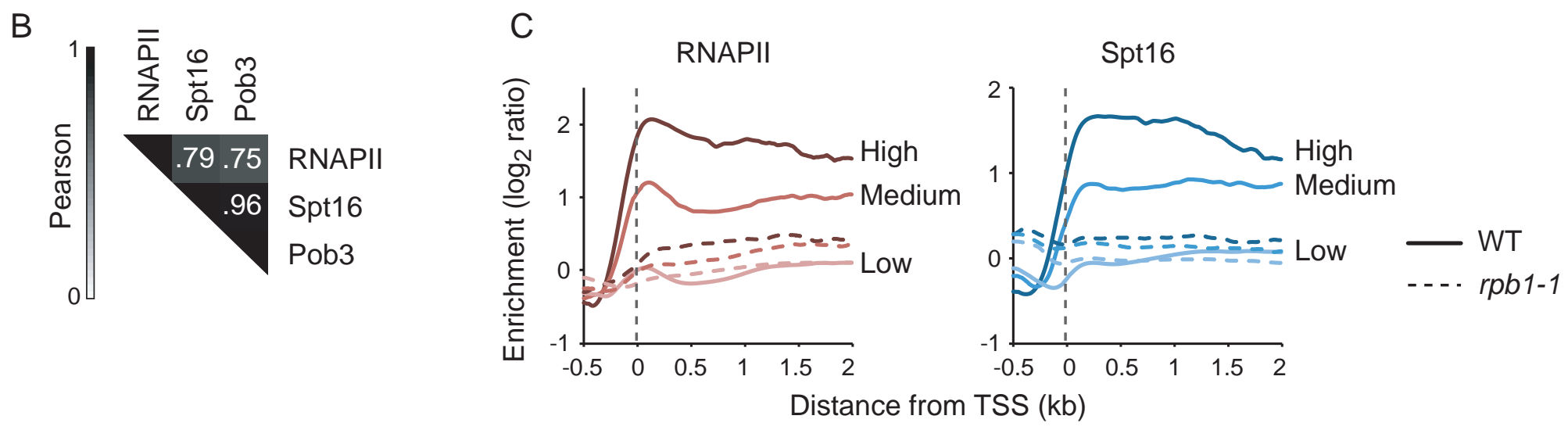

D

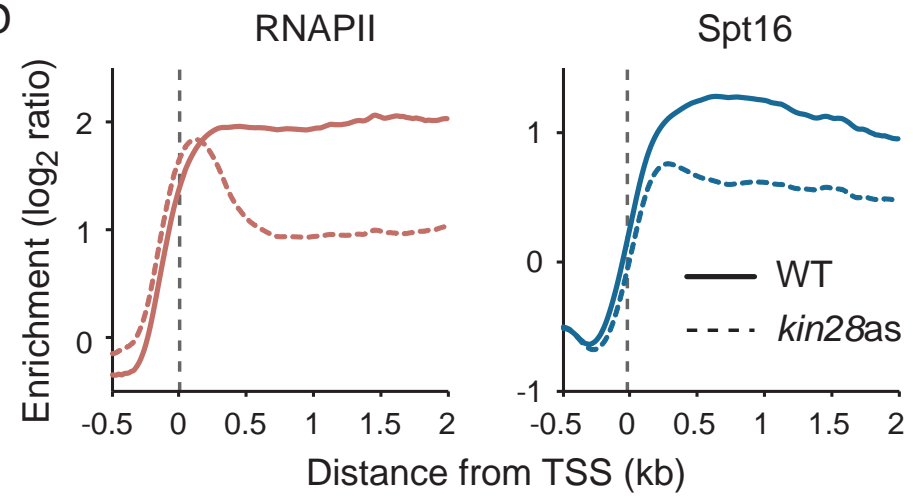

E

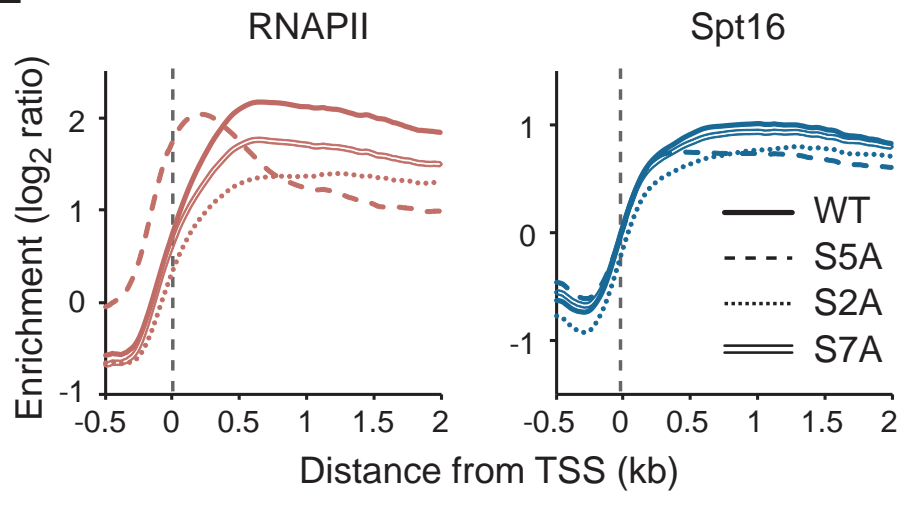


A available under aCC-BY-NC-ND 4.0 International license.

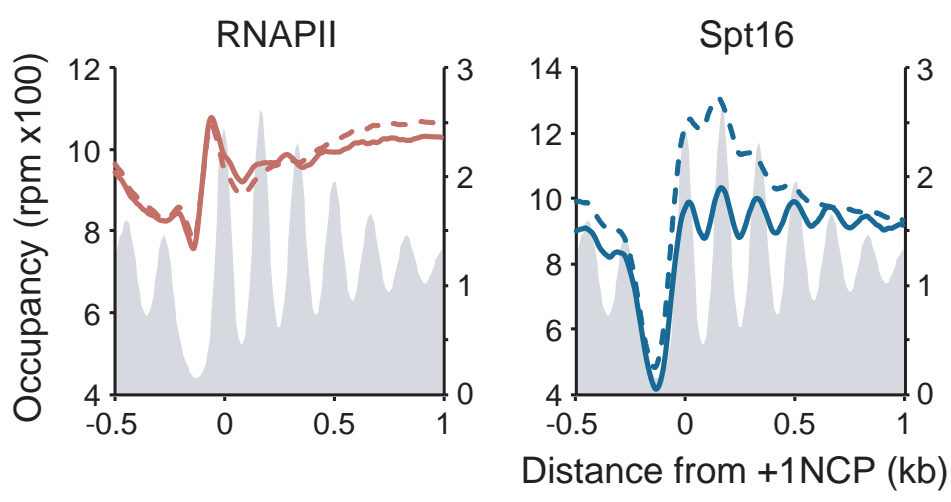

Pob3

B

chd1- $\quad \mathrm{C}$

Chd 1

RNAPII

Spt16
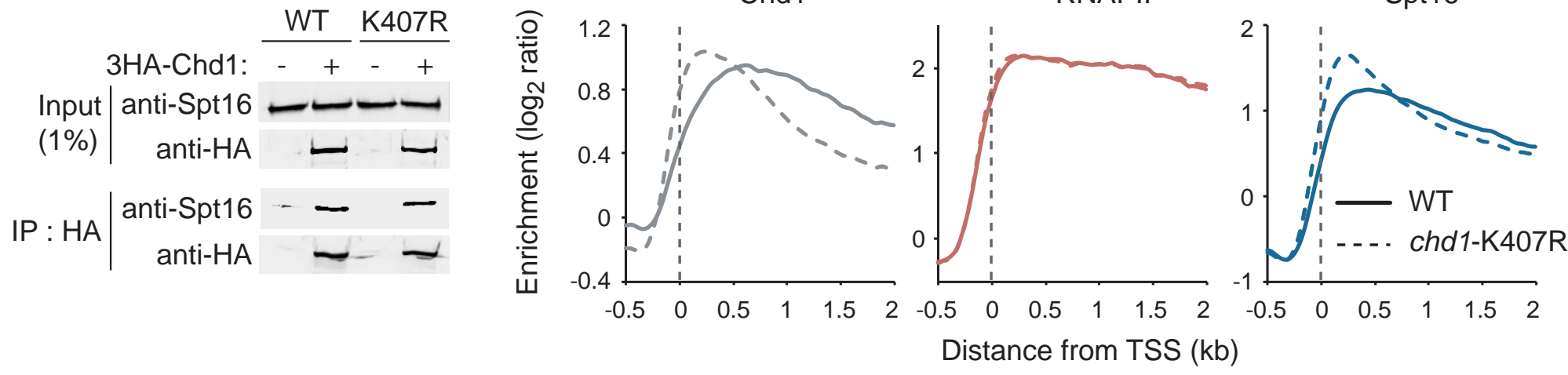

D
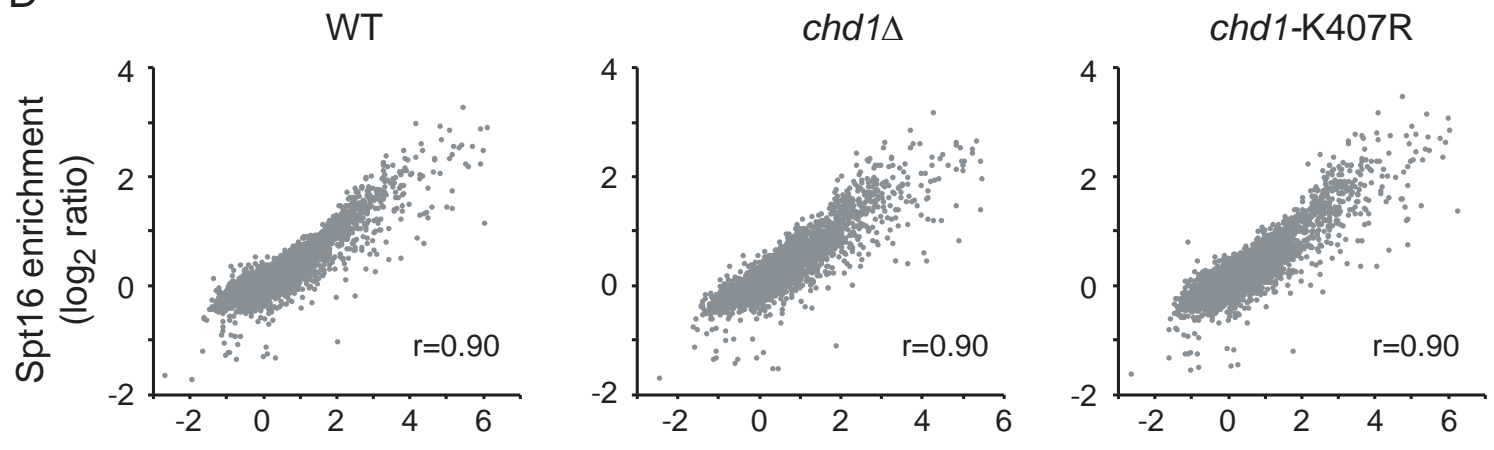

RNAPII enrichment

( $\log _{2}$ ratio) 
bioRxiv preprint doi: https://doi.org/10.1101/2020.08.20.259960; this version posted August 21, 2020. The copyright holder for this preprint (which was not certified by peer review) is the author/funder, who has granted bioRxiv a license to display the preprint in perpetuity. It is made A

\section{All genes} available under aCC-BY-NC-ND 4.0 International license.

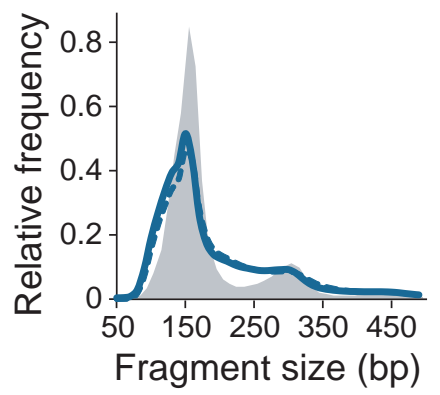
Top $10 \%$

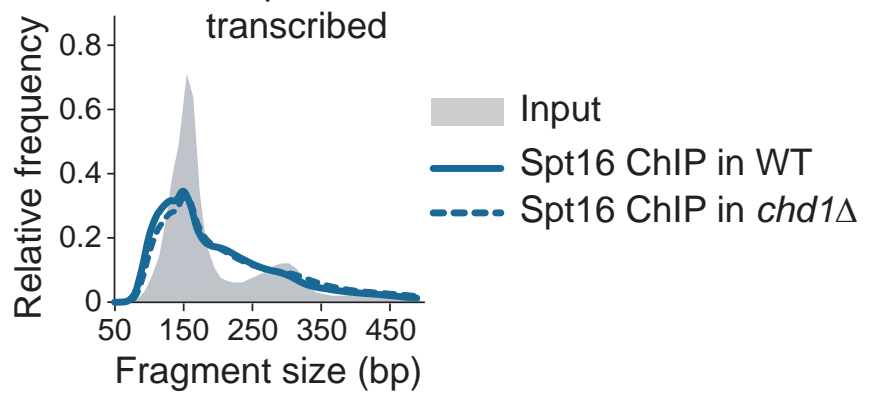

B
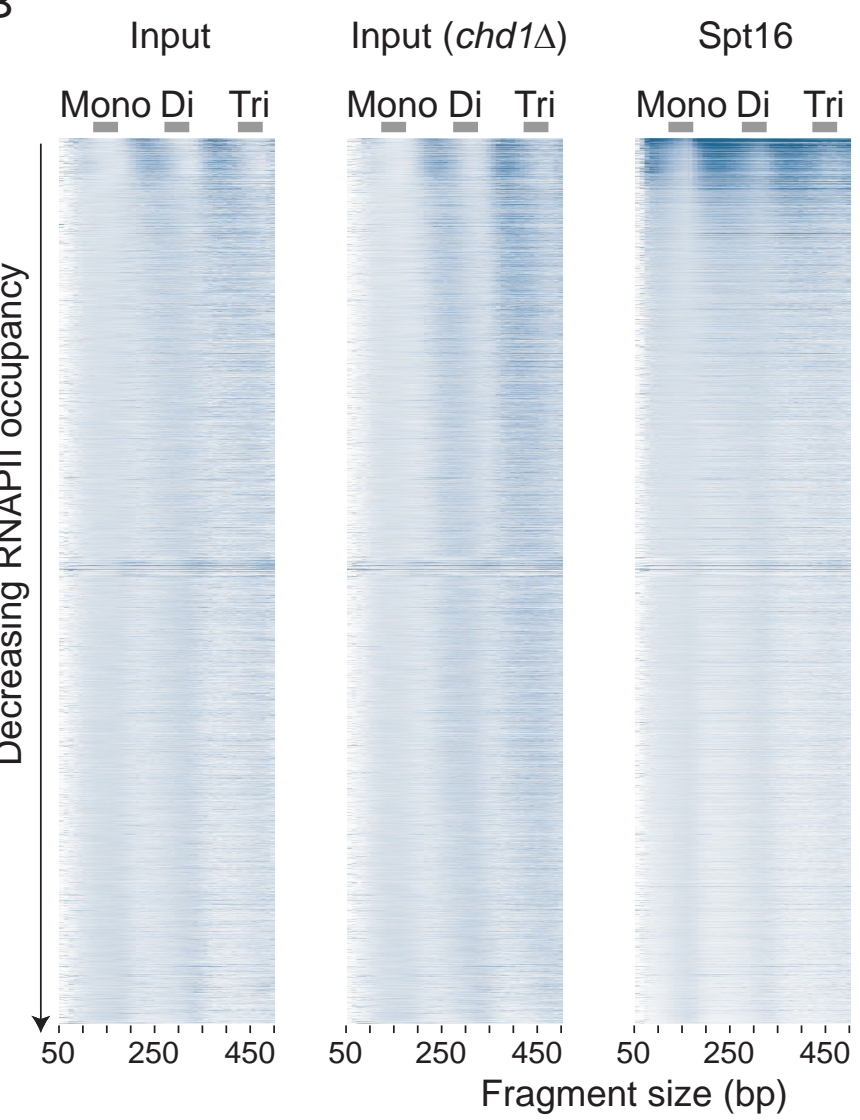

Spt16 (chd1 $\Delta)$

Mono Di Tri

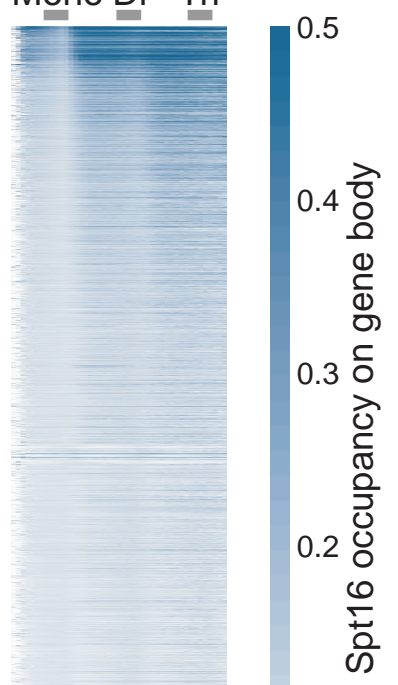

0.1

0 
bioRxiv preprint doi: https://doi.org/10.1101/2020.08.20.259960; this version posted August 21, 2020. The copyright holder for this preprint A (which was not certified by peer review) is the author/funder, who has granted bioRxiv a license to display the preprint in perpetuity. It is made available under aCC-BY-NC-N $\mathrm{N}$. 4.0 International license.
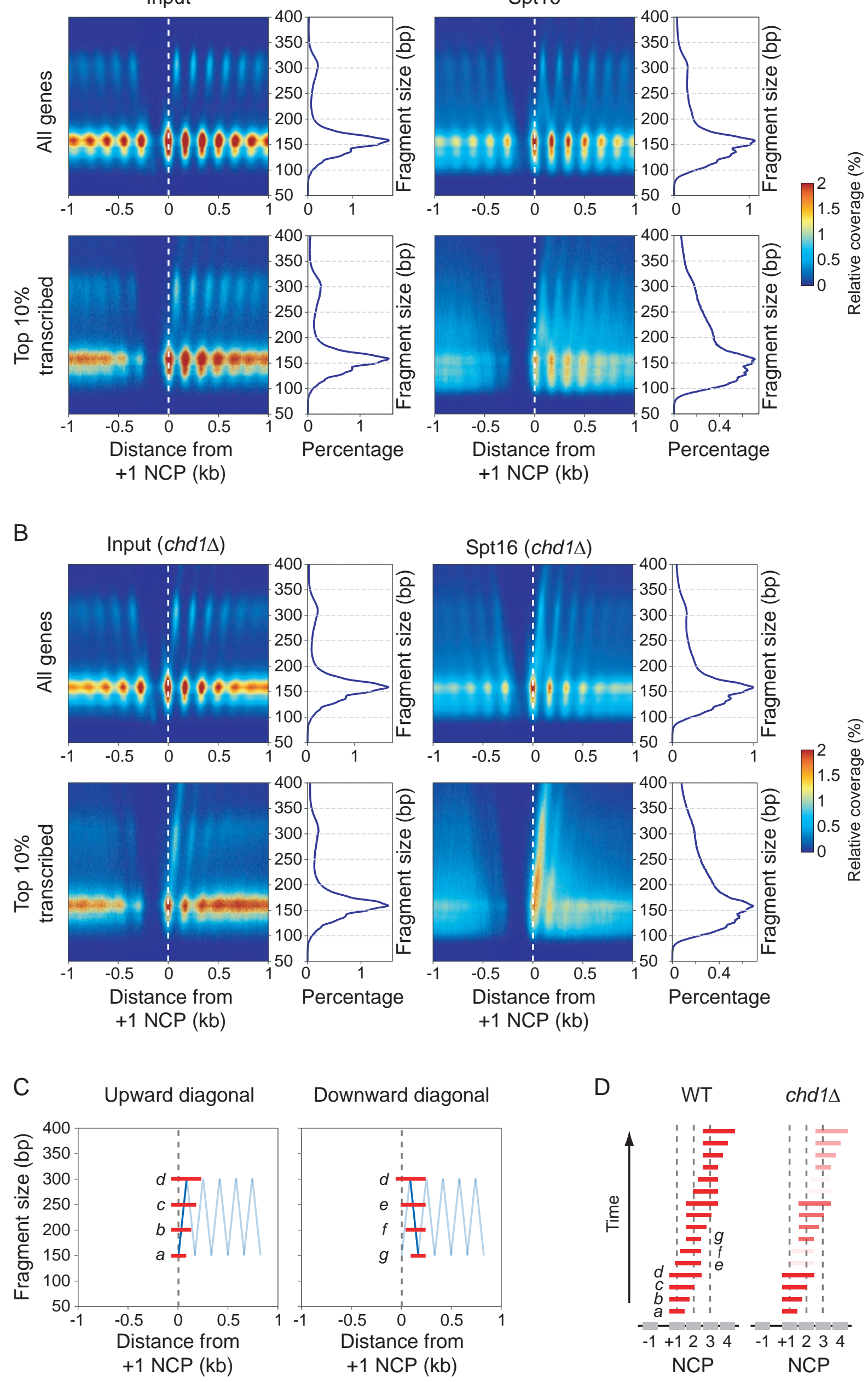
bioRxiv preprint doi: https://doi.org/10.1101/2020.08.20.259960; this version posted August 21, 2020. The copyright holder for this preprint (which was not certified by peer review) is the author/funder, who has granted bioRxiv a license to display the preprint in perpetuity. It is made available under aCC-BY-NC-ND 4.0 International license.

A

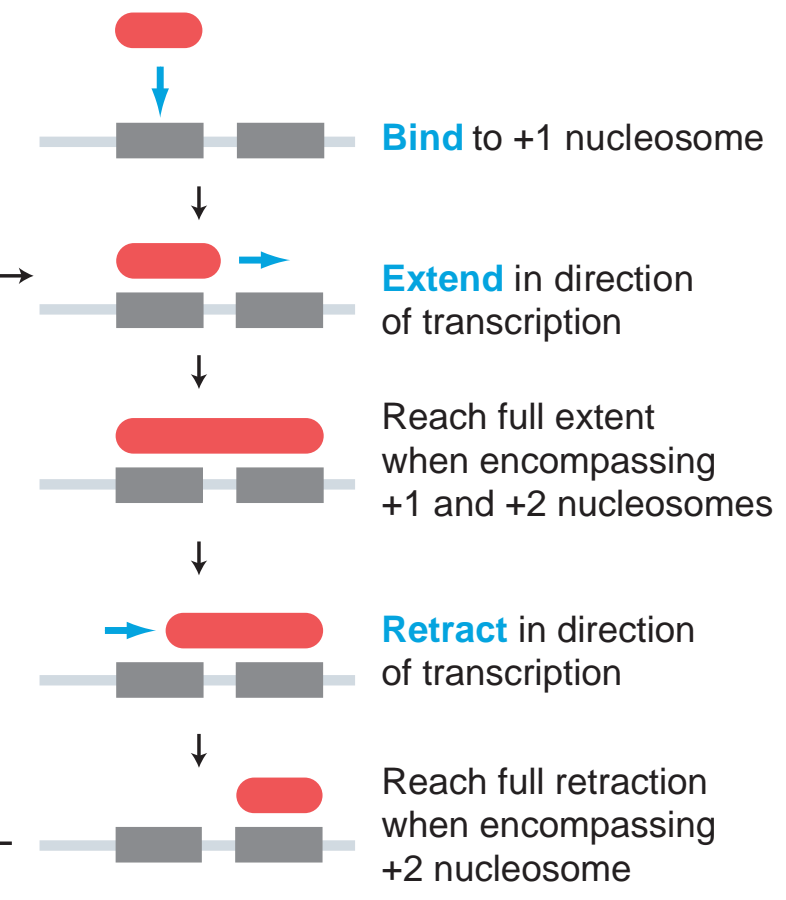

B $\quad$ C

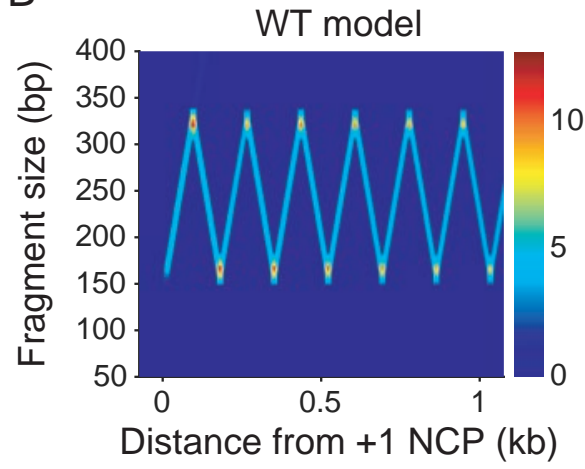

D

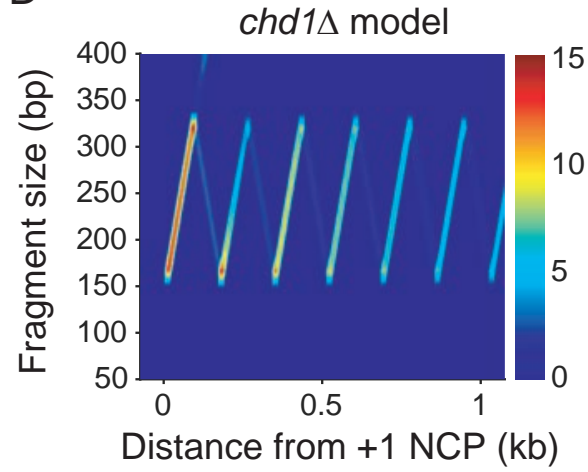

C

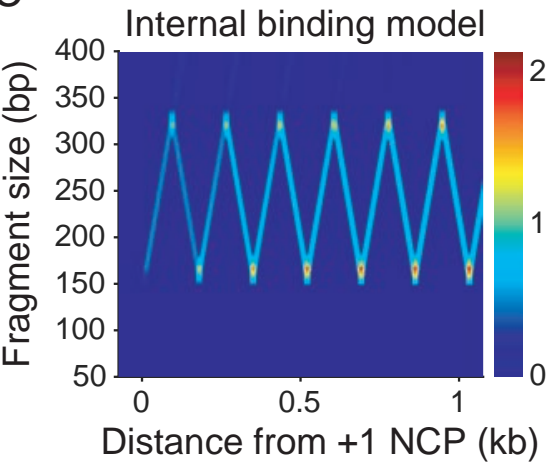


bioRxiv preprint doi: https://doi org/10.1101/2020.08 20.259960; this version posted August 21, 2020. The copyright holder for this preprint (which was not certified by peer review) is the author/funder, who has granted bioRxiv a license to display the preprint in perpetuity. It is made available under aCC-BY-NC-ND 4.0 International license.

TSS-proximal side exposed

distal side exposed

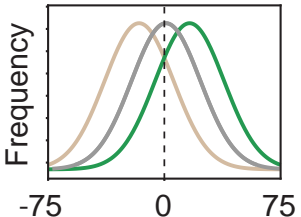

Position relative to dyad $(\mathrm{bp})$
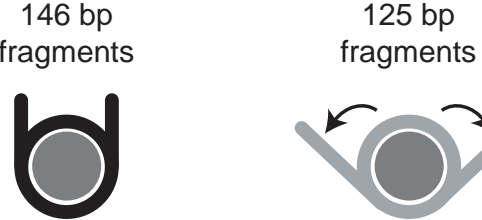

Nucleosome

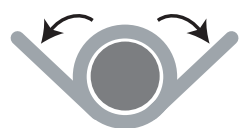

Symetrically unwrapped nucleosome
$103 \mathrm{bp}$ and $90 \mathrm{bp}$ fragments

B

+1 Nucleosome

\begin{tabular}{llllll}
\hline & WT & & \multicolumn{2}{c}{ chd1 } \\
\cline { 5 - 6 } Spt16 & Pob3 & & Spt16 & Pob3
\end{tabular}

$103 \mathrm{bp}$
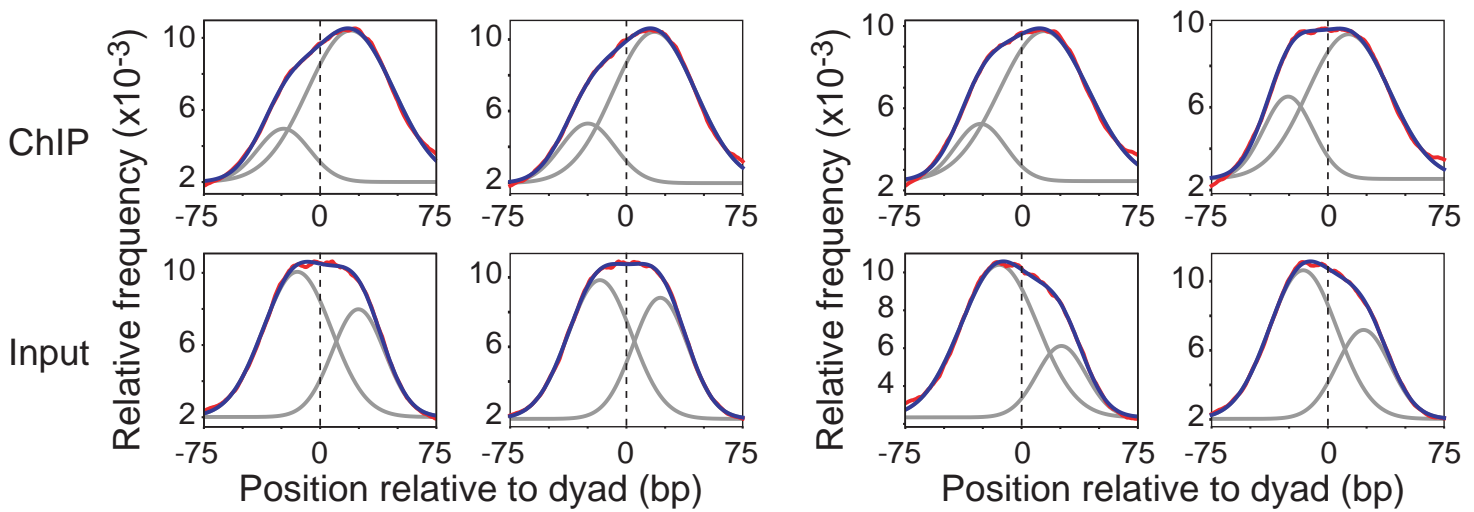

$125 \mathrm{bp}$
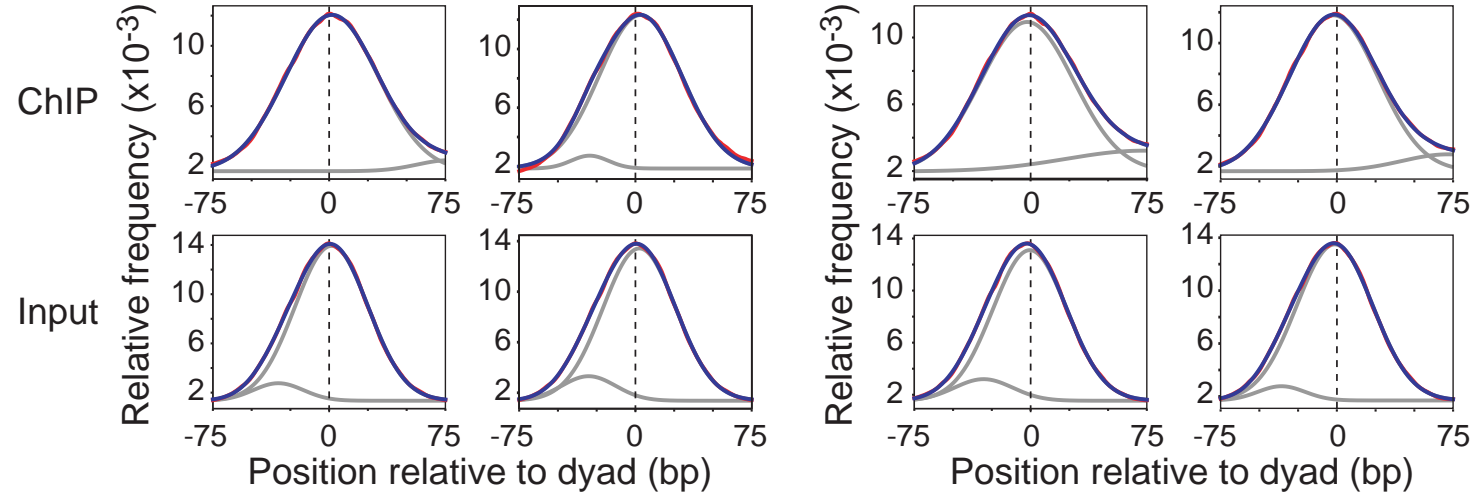

C

Spt16 and RNAPII

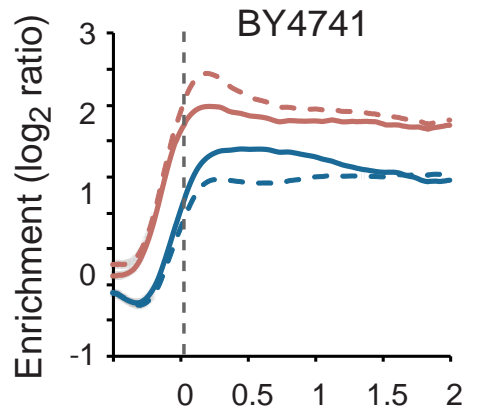

Distance from TSS (kb)
BY4741

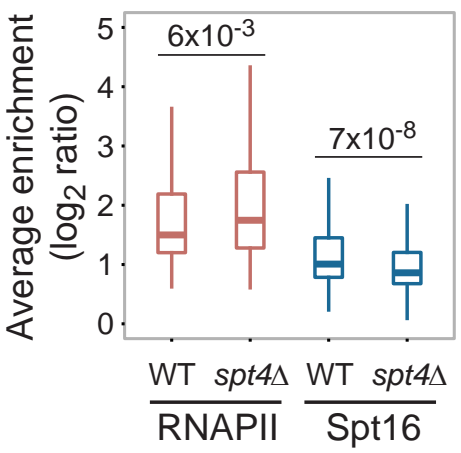

